TITLE:

Testing the Effects of Police Body-Born Cameras on Use of Force during Arrests: A Randomized Controlled Trial in a Large British Police Force

\author{
Darren Henstock $^{\dagger}$ and $\quad$ Barak Ariel ${ }^{\ddagger}$
}

$\dagger$ Cantab. Police Executive Programme, Institute of Criminology, University of Cambridge, Sidgwick Avenue Cambridge CB3 9DA UK, +44.1223.335360, dwh43@ cam.ac.uk

\$ Corresponding author; PhD, Lecturer, Institute of Criminology, Faculty of Law, Hebrew University, Mount Scopus, Jerusalem 91905 Israel, +972.2.5882502;

barak.ariel@mail.huji.ac.il; Lecturer in Experimental Criminology, Institute of Criminology, University of Cambridge, Sidgwick Avenue Cambridge CB3 9DA UK, +44.1223.767378, ba285@cam.ac.uk

The authors declare no conflict of interests 


\section{TESTING THE EFFECTS OF POLICE BODY-BORN CAMERAS ON USE OF FORCE DURING ARRESTS: A RANDOMIZED CONTROLLED TRIAL IN A LARGE BRITISH POLICE FORCE}

\section{HIGHLIGHTS}

- There is, at present, a world-wide uncontrolled social experiment taking place within policing on body-worn-cameras, without much evidence from controlled studies

- Our randomized-controlled-trial aims to reveal the conditions under which body-worncameras can effect arrest dynamics in England and Wales

- Scholars interested in use of force should differentiate between "compliant handcuffs" which are part of the arrest procedure rather than use-of-force per se, and "noncompliant handcuffing", which form a step on the force continuum.

- Overall, the odds of use of force while using body-worn-cameras are $50 \%$ lower than control conditions. However, the effect is statistically significant only when compliant handcuffing is removed from the definition of "use of force".

- Instead, the odds of reporting compliant handcuffing under treatment conditions increased by $40 \%$ compared to control conditions, which is likely to be a result of enhanced police accountability.

- Overall, the effect of body-worn cameras in frontline policing is concentrated on "openend tactics" rather than more aggressive force responses (e.g., batons, Taser discharges, pepper spray, etc.). 


\title{
TESTING THE EFFECTS OF POLICE BODY-BORN CAMERAS ON USE OF FORCE DURING ARRESTS: A RANDOMIZED CONTROLLED TRIAL IN A LARGE BRITISH POLICE FORCE
}

\begin{abstract}
PURPOSE: This study aims to assess the effect of body-worn cameras (BWCs) on police use of force, in a British Police Force context.

METHODS: We tested the effect of BWCs with a large British force in a 6-month randomisedcontrolled-trial. Police shifts $(n=430)$ were randomly assigned on a weekly basis into treatment and control conditions. Odds ratios of use of force rates per arrests were used to estimate the causal impact of BWCs. Analyses of these odds for overall use of force and again within prespecified force categories were conducted.

RESULTS: Overall 50\% reduction in the odds of force used when BWCs are present compared to control conditions. Our estimates suggest a $35 \%$ reduction of overall weighted force in the treatment conditions compared to control conditions. However, the effect concentrates in openhand tactics (physical restraints and non-compliant handcuffing), with no discernible effect on categories of more aggressive force-responses (e.g., dogs, Taser, batons, pepper spray). Forty per cent "more force" was detected in treatment conditions for handcuffing non-combatant suspects.

CONCLUSIONS: BWCS deter officers, offenders, or both, into complaint behaviour. Importantly, showing a conditional effect on force types can be further contextualized as enhanced transparency and accountability by the police, with greater reporting of use of force that would otherwise be concealed. Our findings illustrate the importance of analysing police use of force with and without compliant handcuffing of arrestees, which may or may not form part of the force continuum.
\end{abstract}

\section{KEY WORDS:}

Body-Worn Cameras, Police, Use of force, experiment, United Kingdom, force continuum 


\section{INTRODUCTION}

Since 2012, police Body-Worn-Cameras (BWCs) have received extensive media attention across the globe (Cubitt et al 2016; Lum et al 2015). All continents have a large number of law enforcement agencies either using or piloting BWCs. These small devices are perceived by many to be a promising way to achieve several aims in law enforcement, including reducing citizen complaints, reducing incidents of use of force, improving evidence gathering, improving public confidence and improving officers' self-legitimacy (White 2014). In the US, the use of BWCs has been recognized by the US White House and the President's Task Force on 21st Century Policing (COPS 2015). Another example for the reach of BWCs is the $12^{\text {th }}$ August 2013 by Judge Shira A. Scheindlin of the Federal District Court in Manhattan, who ordered the NYPD to set up a one-year pilot program that would compel officers to wear cameras in the precincts where the most police stops were being performed (NY Times 12/08/2013). In Europe, the UK College of Policing suggested that BWCs were the mechanism through which "dented public confidence" could be restored (BBC 24/10/2013). The idea that BWCs are an inevitable necessity and will soon be commonplace equipment for police officers is currently propagated in the media and driven by its manufacturers (Stratton et al 2014).

Despite these laudable claims, there is a shortage of evidence on the benefits of the BWC. A literature review of the evidence on the effectiveness of BWCs has suggested that, "despite vast information sources discussing BWC technology the operational evidence to support claims about either the pros or cons of this technology is sparse." (Lum et al 2015; Stratton et al 2014:13).

Of particular interest is the potential impact of these devices on police use of force, particularly at a time when police killings seem to be on the rise (Guardian 01/06/2015). Indeed, public as well as political interest in the possible effect of BWCs on police use of force is not surprising (Goldsmith 2010; Collins 2009). Use of force is a powerful talisman for those publicizing the wrongs of various police forces; a trawl of the internet reveals numerous videos of perceived police brutality (e.g., Brown 2015). While most UK forces have a greater level of public support than their US counterparts, there are nevertheless pockets, in most forces, where mistrust and lack of confidence characterize the community's perception of the police (Ariel 2016). Various scholars (Terrill 2001; Geller and Toch 1996; Skolnick and Fyfe 1993) argue how officers' use of force damages the public-police contract. Tensions that arise if the police 
break this contract and the potentially catastrophic results that may follow can predicate social upheaval; the riots after the deaths of Rodney King (1992), Mark Duggan (2011), Michael Brown in Ferguson County, Missouri, as well as Alton Sterling in Louisiana (2016) and Philando Castile in Minnesota (2016). Thus, anything that can strengthen and reinforce the police-public contract is vitally important to modern police forces.

BWCs have entered this discourse with a bang. To illustrate, while most agencies in the Western world are facing austerity measures, the Obama administration recently proposed spending \$263 million on supporting the deployment of 50,000 cameras in the US (US Justice Department 1/05/15). Similarly, the Metropolitan Police announced the deploying of 20,000 cameras at significant cost to the taxpayer (BBC 3/06/15; Greater London Authority 24/06/15). We suspect that most law-enforcement agencies worldwide will embark on a similar journey by massively purchasing these devices, in just a few years.

Much like other pivotal moments in criminal justice research history (e.g., Sherman and Berk 1984), the opportunity exists to help guide policy with evidence. Yet the scope of research on these devices is limited, but is also underpinned by evidence which reflects varying degrees of methodological rigor (Lum et al 2015). Thus far, there have only been only a handful of published experiments on the effect of BWCs on police use of force: first there is the Rialto study (Ariel, Farrar and Sutherland 2014) and the Cambridge University replication studies (Ariel et al., 2016a, 2016b, 2016c). Second, a notable study was conducted in Meza (Ready and Young, 2015), and (third), the Orlando Experiment (Jennings, Lynch and Fridell 2015). There have also been a few quasi-experiments (e.g., Katz et al 2014), but overall the literature is not characterized by the mature body of rigorous evidence such as the hot spots experiments (Braga et al 2012) or face to face restorative justice conferencing (Sherman et al 2015). To the best of our knowledge, there have been no published rigorous tests of the effect of BWCs, under satisfactory controlled settings, outside the US. This study is the first completed test of BWCs in a British metropolitan police force, aiming to replicate the Rialto study in a large force and within specific settings. This study also seeks to complicate the Rialto study with a more granular analysis of "force" - not simply as a dichotomous outcome, but rather as a scale, with greater emphasis on force categories than a binary variable. As we argue, these analyses echo theoretical debates about policing in late modernity, including accountability, transparency and social control practices more broadly. 
We begin by briefly reviewing the relevant literature on police use of force, followed by a review of the literature on BWCs. We pay particular attention to ways in which these devices are hypothesized to reduce the prevalence and severity of force in police-public contacts. We then move on to describe the methods we used to estimate the causal inference of the effect of the devices on police use of force, and how we captured data on these incidents. A manual read of 590 arrest records that had taken place during the experimental period, some with and some without logs on use of force, injuries to suspects and details about the interaction - which are captured independently by custody officers as part of their routine booking procedures - was conducted, in order to identify various dimensions of these aggressive encounters. The outcomes are presented next, followed by a discussion of the findings for future research and considerations for implementation of BWCs in police departments worldwide.

\section{POLICE USE OF FORCE}

The Peelian principles that underpin modern policing suggest that the degree to which public co-operation can be secured diminishes proportionately to the necessity of the use of physical force by the police. Policing by consent means that the police should only use physical force to the extent necessary to secure observance of the law, or to restore order, when the exercise of persuasion, advice and warning is found to be insufficient (Lentz 2007). To that effect, Bittner (1970:38) contended that "no matter what task the police are involved with, police intervention means making use of the authority and ability to overpower resistance." Since this auspicious statement was made, there have been multiple studies of the many aspects of police use of force (Wolf et al 2009, Alpert and Dunham 1997, 2004; Sherman 1980, Garner et al 2002; Reiss 1968). Ariel et al (2014:511) suggested that "this scholastic interest reflects significant investment by practitioners and decision-makers in better understanding the ways in which law enforcement institutions exercise their power, and how such powers are managed." Society presents the police force with a paradox in that in order to stop violence, police officers may have to use violence (Sherman 1980). Indeed, some researchers have claimed that the reason people call the police for help is based on their belief that force may be necessary (Langworthy and Travis 1999). Collectively, these considerations defend the view that police work $i$ inevitably about the application of force, when needed. 
Far less agreement in the literature exists about how to understand the application of these police powers in police work. We review some of these postulations and evidence below. However it is important to note that, within the spectrum of use of force there are two situations which are deemed to be unequivocally undesirable; excessive use of force and unnecessary use of force. Either situation is argued to undermine and damage the police' relationship with the community (Ariel et al 2016b; Reiss 1968; Worden 1996). "Complaints about police conduct do not usually arise because police are apprehending burglars in the middle of the night, or robbers holding up a bank. Trouble arises out of social interaction..." (Skolnick and Fyfe 1993: 97). Within this prism, it becomes effectively clear why any method by which excessive, nonproportional or altogether unnecessary application of force can be reduced, would be a desired outcome.

Terrill (2001:14) explores several explanatory perspectives in the understanding of police use of force that he derives from the social science literature of the last 40 years. There are numerous cues which officers recognize, as well as countless interactions between these variables, that lead to the use of force (Terrill and Mastrofski 2002; Wikstrom et al 2012; Hickman et al, 2008; Garner et al 2002). Simply listing them, however, does not aid in explaining the use of force, although understanding their relevance to police actions is, nevertheless, important. Conceptually speaking, the broad range of variables that constitutes "use of force" can be categorized as situational, psychological and organizational.

Situational cues can prompt officers to make assessments about how an incident should be handled and how much "force" should be applied (Sherman 1980; Black 1976; Ariel and Tankebe 2016). These cues might be the race, gender, age, demeanour, sobriety or mental state of the suspect. The ecological circumstances of the interaction play a part here, such as the neighbourhood in which the police and suspect interact, lighting, availability of CCTV, or the number of bystanders or officers involved. These cues can be considered the theatre in which the encounter takes place. Reiss (1968) found that $78 \%$ of the time force occurred in policecontrolled settings, such as within the police vehicle, precinct or public streets; and in the majority of cases, there are no witnesses. Research has further expanded this view, suggesting it is the suspects' actions and resistance during the encounter that precipitate the level of force used by officers (Alpert and Dunham 1997; Alpert et al, 2004; Terrill 2001). This is the 'demeanour hypothesis' (see Engel, Sobol and Worden 2000; Worden and Shepard 1996; 
Worden, Shepard and Mastrofski 1996), which is one of the leading predictors of police use of force.

A psychological perspective suggests that it is the officers' personal characteristics, experiences, views, training and outlook, which determine the application of force (Terrill 2001). There is evidence to suggest some officers are more aggressive in stressful situations whilst some officers show greater restraint when confronted by disrespectful conduct (Engel 2000). In another study, aggressiveness and tough-minded characteristics in officers were predictors of greater use of force (Fabricatore et al 1978). Worden (1995) found that officers who were university graduates were more likely to use physical force. The wealth of research in this area suggests that psychological variables are important to any study of the use of force, but we recognize that this area is understudied.

Finally, research on use of force applied two predominant organizational theories to understand what may influence officers' use of excessive or unnecessary force. Wilson (1968) proposed an organizational theory that reflects on the corporate structures and political environment of the time. The model suggests that officers will tend to act similarly to given situations due to organizational rules, regulations, standard operating procedures, incentives and top-down managerial models. A style of policing develops with a "common vision that becomes part of each officer's mind-set of how to handle everyday aspects of policing" (Terrill 2001:20). Therefore, in agencies where there is an overall official acceptance to use more force against suspects (or specific types of suspects), more officers are more likely to exhibit this pattern of behaviour. The second theory looks at police subculture (Brown 1998; Skolnick 2008; Baker 1985) and presumes that it allows officers to operate with some impunity, as there is tacit approval of their actions by colleagues and a reluctance to inform on what is seen as appropriate. Baker (1985) summarized this in his "hierarchy of wrongfulness": "dead wrong; wrong, but not bad; wrong but everybody does it." Some authors (Ariel et al 2014) have described this as being how officers see excessive or unnecessary force, but as Skolnick (2008) points out, officers are now more culturally diverse than in 1985, which may distort the neatness of this model. Either way, it seems clear that when considering use of force one cannot solely concentrate on officers and suspects, there needs to be consideration of the organizational environment in which they operate. 


\section{Measuring Police Use of Force}

When an officer uses "force", he or she is nearly always required to file an official report, even if only in his or her pocketbook. In many UK forces, the custody officer who is in charge of booking arrestees, is responsible for recording incidents of use of force as well, including any sustained injuries to suspects, as a result of the use of force. The challenge however, is that not every physical action on the part of an officer is considered "force." The very definition can be subjective, memory-prone, generally unclear and primarily an intradepartmental measure. This suggests to us that the reporting of use of force is closely linked to police accountability and transparency. Sound reporting of accurate and full account use of force is the cornerstone of police accountability and is essential if officers are to be held responsible for their actions, regardless of whether or not those actions were justified. As reviewed by other scholars (Mastrofski 2002; Ransley, Anderson \& Prenzler 2007; Stenning 2009), police accountability refers to taking responsibility for the actions of the organization by tracking or measuring its outputs. This requirement demands that the police are accountable for their performance, and will amend it when necessary. The police must act in the public's interest, and are therefore assumed to be held to a higher degree of accountability than citizens - especially given the wide powers they hold in modern society (Bayley 1996; Skolnick and Fyfe 1993; Kupferberg 2008; Walsh 2001). For this and other reasons, Walker 2007:5 (see also Walker and Archbold 2013:94) contends that:

[T] he first accountability procedure to be considered involves the direction and control officer use of police authority through formal agency policies. This approach, generically known as administrative rulemaking, is a basic feature of modern police management, if not all public and private sector organizations. Administrative rulemaking consists of three elements: specifying approved and forbidden actions in written policies; requiring officers to file written reports on specific actions; requiring administrative review of officer reports.

Some ethnographic work in this area (e.g., Hunt 1985; Rojek et al 2012) suggests that what is construed as a "reportable incident of force" and how much force is appropriate, is often predicated by a police department's organizational culture. For example, police 
subculture in relation to the reporting of use-of-force plays a role in accepting or allowing "force" to be applied in certain circumstances. Researchers who study police organizations have made the case for some time now that use-of-force and its subsequent reporting are a function of police officers' attitudinal commitment to certain institutional or organizational cultures around their roles in society and, more broadly, their views of power (Terrill et al 2003; Lester 1996). Certain institutional and subcultural codes make police agencies particularly resistant to cultural changes and transparency requirements (Skolnick 2008:37). Feelings of loyalty sustain this code of silence and make it particularly difficult to investigate purported unnecessary, or excessive, use-of-force, especially when it goes unrecorded (Baker 1985:210-213). For example, placing one's hand on another's shoulder in an authoritative way, or using handcuffs, may be considered use-of-force in some instances and for some individuals, whereas for others they may not. Aggressive voice commends (shouting, cursing, and threats) can certainly be construed as "force" as well, however not all police forces hold the view that such commands are recordable acts of force. In similar ways, measuring "injury" or "assault" is also likely to be challenged in terms of definitional threshold, as it is open to interpretation when there are no clear signs of physical contact. Taken collectively, we see that what needs to be reported, or not, is not always as clear-cut as it could be, yet it does form a direct and tangible aspect of police transparency.

Recording issues also present problems when trying to identify the scope of use of force in policing. On the one hand, there seems to be an agreement that, in general, officers do not use force as often as the popular media usually suggests, since the majority of officers' daily contacts are with law-abiding citizens (Alpert \& Dunham 2004; Croft 1985; Fyfe 1988; Bayley $\&$ Garofolo 1989). On the other hand, there are organizational pressures and biases that mask the true levels of use of force prevalence, frequency and severity (Alpert and Smith 1999). Adams (1996:62) suggests use of force "happens twice as often" as is suggested by official reports, particularly "low level" use of force, such as verbal commands or simply taking hold of someone. Still, measuring what "police force" is, at which point it becomes excessive, unnecessary or disproportional (Worden 1996; Reiss 1968) - or even who instigates the use of force beyond what is required - is far from clear (Ariel et al 2016c). No tracking system of force is completely reliable and valid; the amount of "force" necessary in any given situation is subjective (Hickman, Piquero \& Garner 2008). 
Thus, police use of some force is an essential requirement against certain offenders, under specific circumstances. The ever-present challenge is to minimize the prevalence, frequency and severity of "force" to its minimal level, without putting officers" lives at risk, whilst still allowing them to gain control in situations when "force" is required (Ariel et al. 2016d). Enhancing proper recording of every force response, no matter at which "severity level" or category, would be an equally desired consequence of a professional agency.

\section{THE DETERRENT EFFECT OF BWC ON POLICE USE OF FORCE}

At this juncture, BWCs come in. The mechanism behind the hypothesized effect of BWCs on use of force is deterrence, driven by the awareness of observation (see Ariel et al. 2016e). There is a wealth of research dealing with how living creatures amend or change their behaviour when they think they are being watched (Chatrand and Bargh 1999; Dzieweczynski et al 2006; Wicklund 1975; Munger and Shelby 1989). A social-cognitive process is engendered by the belief, or awareness, of being under observation and is expressed by an increased desire to observe societal rules; this is often manifested by an observable increase in conformity to acceptable behaviour patterns (Gervais and Norenzayan 2012; Sproull et al 1996; Barclay 2004). People understand that rule breaking is a behaviour that can lead to sanctions, and is therefore something that should be avoided (Klepper and Nagin 2006; Nagin 2013a). Kahneman (2011) explains that although genuinely strict rationality in all decision-making is unobtainable by most people, it is nevertheless true that certain cues (even very small ones) that someone is watching, can lead to positive reactions and improved behaviour as non-compliant behaviour can lead to adverse consequences which, ultimately, rational actors wish to circumvent.

In criminology, these notions are more widely studied within the framework of deterrence theory (see Ariel et al., 2016d). Deterrence theory dictates that the threat of apprehension is causally linked to more compliance and/or less rule breaking. Police officers and scholars equally assume that the threat of immediate incarceration, or at least interdiction, deters non-compliance. This model is believed to be universal, so it is expected to work on both suspects/offenders as well as police officers. As Durlauf and Nagin (2011:7) write, "for criminal decisions, what matters is the subjective probability a potential criminal assigns to apprehension" (see also Groff et al 2015). Nagin (2013a, 2013b), Loughran, Pogarsky, Piquero, 
and Paternoster (2012), and more recently Nagin, Solow and Lum (2015) have shown some of the necessary conditions in which deterrence exerts an effect on criminal decision-making, and the same can be said for officers who must comply with police regulations. Getting caught doing something morally or socially wrong is often registered as behaviour that can potentially lead to negative consequences, which is an outcome people often flight from. Studies have, nevertheless, uncovered a propensity to avoid negative outcomes, and findings generally agree that individuals react compliantly to even the slightest cues indicating that somebody may be watching: being watched is registered as an antecedent to a likely apprehension and therefore this awareness encapsulates a tangible deterrence effect (Dzieweczynski et al 2006).

Thus, deterrence and the awareness of observation work equally on suspects who would otherwise decide to commit a crime and on police officers who might otherwise break the rules of conduct. For this reason, BWCs are hypothesized to work simultaneously on both actors in a police-public encounter. When officers and suspects are cognizant of the BWC, they are equally assumed to have no preference towards rule breaking, as the risk apprehension and conviction by the evidence captured on videotape is overwhelming. BWCs, unlike CCTV, dashboard cameras or bystanders' mobile-phone cameras, can be viewed as "credible threats" (Jervis et al 1989:3; Nagin 2013a): Parties in the interaction are conscious not only of the fact that they are being watched, but also of the consequences associated with non-compliance. "Getting-away" with rule breakzing is far less conceivable if one is being videotaped and one is conscious that the behaviour is in fact videotaped. The evidence from the Rialto study supports this model.

\section{What We Know about BWC and the Rialto Experiment}

There have been four literature reviews (Cubitt et al 2016; Lum et al 2015; Stratton et al 2014; White 2014) published on BWCs, and since these publications, additional reports have been released from the Cambridge University replication studies (Ariel et al. 2016a, 2016b, 2016c, 2016d). If read together, cover the entire gamut of the research on BWCs to date. Of these, only but a handful randomized controlled trial (RCT) on the effectiveness of BWCs achieves the requirements of Level 5, in terms of its scientific rigor, on the Maryland Scientific Methods Scale (Sherman et al 1998). The first was a randomized controlled trial, known as the Rialto Experiment, looked at the effectiveness of BWCs in Rialto, California, with specific 
focus on use of force and complaints. Rialto Police Department, a small jurisdiction in California with just over 50 frontline officers, compared nearly 500 police shifts during which all police-public encounters were equally assigned to either treatment or control conditions. During treatment shifts, Rialto officers were asked to videotape all their encounters with members of the public and to store evidence on a secured cloud. In control shifts, the officers were tasked never to use the devices. Outcomes were then measured, in terms of officially recorded use of force incidents and complaints lodged against Rialto police officers. Following this 12-month experiment, Ariel, Farrar and Sutherland (2014) reported a relative reduction of roughly $50 \%$ in the total number of incidents of use-of-force compared to control conditions, and a 90\% reduction in citizens' complaints, compared to the 12 -months prior to the experiment.

The findings from the Rialto study have generated heated debates worldwide (Reddit 24/12/14), particularly concerning the transferability of the findings to other jurisdictions, or to larger police departments (Miller et al 2014; NY Times 24/09/14). Questions have also been raised as to whether unique circumstances in Rialto jeopardized the external validity of the test (BenBrucato.com 3/12/14). Major metropolitan cities, and with them large law enforcement agencies, operate on a different scale to small or even medium sized forces (Regale et al 1989; Corner 1989; Weber-Brookes \& Lieber-Piquero 1998). Likewise, whether or not these US findings are transferable abroad has also been raised. White (2014:10) concluded that:

[I]ndependent research on body-worn camera technology is urgently needed. Most of the claims made by advocates and critics of the technology remain untested ... Researchers should examine all aspects of the implementation and impact of the technology - from its perceived civilizing effect, evidentiary benefits, and impact on citizen perceptions of police legitimacy to its consequences for privacy rights, the law enforcement agency, and other outside stakeholders.

The Mesa study (Ready and Young) conducted an experiment with the Mesa, Arizona Police Department. The study analysed nearly 3,700 field reports completed by 100 sworn patrol officers. Random assignment of the officers into treatment and control groups have resulted in several important findings: first, officers that did not wear body worn videos were more likely to conduct stop and search, and were also more likely to make an arrest. This means that wearing BWCs may cause officers to be more cautious and risk-averse than control 
conditions. At the same time, treatment officers were more likely to give citations and initiate encounters. This suggests that BWCs may cause officers to be more proactive with this technology, however without increasing their use of invasive strategies that "may threaten the legitimacy of the organisation" (Ready and Young 2015: 445).

Finally, Jennings, Lynch and Fridell (2015) have also observed the effect of BWCs on policing, but focused particularly on response-to-resistance incidents. in their randomised experiment, they have used 46 officers who were randomly assigned to wear BWCs and 43 officers who were randomly assigned to not wear BWCs. the study has shown that BWCs reduced these types of incidents and serious external complaints. The prevalence of responseto-resistance incidents and the prevalence and frequency of serious external complaints were significantly less for officers randomly assigned to wear BWCs (p. 480).

These three tests are all American. Experimental replications are also required in order to show whether its findings represent an US-centric anomaly attributable to the US contexts only, or due to the novelty of these devices in American police operations, or both.

To be fair, noteworthy non-RCT studies, nevertheless, do exist on BWCs. The United Kingdom police forces were in fact the first to express an interest in BWCs. The Plymouth Head Camera Project (Goodall 2007); the Grampian Police study (ODS Consulting 2011); Project Hyperion study in Hampshire (Ellis 2014) - all these Level 1 or 2 studies on the Maryland Scale offer some confirmation of the hypothesized effect of BWCs on the incidence of use of force. Although these non-controlled before-after studies did not look directly at use of force, they have nonetheless reported reductions in crime, fewer assaults on officers and improvements in criminal justice outcomes. At the same time, these studies suffer from risks to internal validity and their results are, consequently, suspect. Another recent evaluative report on BWCs, conducted in the county of Essex by The College of Policing (Owens et al 2014), has proved inconclusive due to challenges in the implementation of the experiment. The study was beset with detrimental implementation issues, such as low usage of the cameras, which damaged both its treatment integrity as well as internal validity and hence rendered the results obtained as challenging to interpret accurately.

\section{Missing Gaps in the Literature on BWCs}


Beyond replications, there are two areas where the available research is lacking and requires a more granular analysis of the effect of BWCs on police use of force. Firstly, a coherent breakdown of what "force" means, beyond the dichotomous measure of self-reported use of force observed in previous studies, is needed and, secondly, a distinction between the compliant and non-compliant handcuffing of suspects, must be made and described.

Not all Force Responses are Created Equal. Once BWCs are mandated in police operations, is there a reduction in the frequency and severity of the use of force? This question about the effects of BWCs on the use of force demands that a closer observation be made about the types of forces that officers are more, or less, likely to use when BWCs are present. Outcome variations are currently unclear. On the one hand, BWCs could also have an effect on any level of force the police use. This implies that BWCs have an effect on all categories of force. On the other hand, the effect of BWCs might be located in the lower bands of what is referred to as the "force continuum" (for a more elaborate review, see Terrill 2001) - e.g., verbal commands, empty-hand submission techniques and some aggressive response techniques such as pepper spray or baton use. The force continuum is a standard that provides police officers with a guideline about how much "force" is appropriate against a resisting suspect, in different circumstances. As such, and under this line of theorization on the effect of BWCs, BWCs are effective, but only up to the point where "force apparatus" such as intermediate weapons (TASER discharges), dogs or lethal force, are used. Put differently, BWCs would only have an effect in instances when the officer was able to convince the suspect to 'step down' using open-hand approaches, and therefore avoid the incremental use of force up to the point where these "force apparatus" are applied.

To be sure, one should anticipate that some suspects are likely to be aggressive anyway, so more forceful responses would be deployed regardless of whether BWCs were present or not. To illustrate, deterrence relies heavily on rational calculations and awareness; for this reason, intoxicated or psychotic offenders are unlikely to be responsive to deterrent messages or the credible threat of punishment through their videotaped demeanour. These cases, which may anyway require extreme measures of police force, would be unsusceptible to the effect of BWCs.

"Compliant" versus "Non-Compliant" Handcuffing. The other crucial element, which has been ignored in previous BWC studies, is the distinction between arrests where the suspect 
is handcuffed and "voluntarily" agreed to go to the station, or circumstances in which the suspect is handcuffed but involuntarily escorted to a police station for further questioning. From a procedural perspective, the use of handcuffs is not legally mandated (College of Policing 2013, 2015), and the suspect may in fact submit without the use of handcuffs. However, in practice - and particularly when patrol officers tour in solo formations - nearly all arrests should result in handcuffing of suspects, simply because this is the health and safety guidance given to officers (Home Office 2014). Whether or not this is good practice is not the issue here, but if these restraints are or are not recorded by the officer as "use of force", they create a measurement bias that needs to be addressed. Departmental and jurisdictional guidance on whether or not these handcuffing practices constitute police "use of force" diverges, and different approaches thus emerge (e.g., see guidelines of West Yorkshire Police, 2011; Las Vegas MPD, 2011, Warwickshire PCC Office, 5/6/15).

Why are we placing so much attention on this seemingly technical aspect? Because measuring any handcuffing as a level of force that requires the officer to log a "use of force" report, or alternatively a policy that stipulates that compliant handcuffing is not use of force, but a non-compliant handcuffing is a recordable event, changes the result. Both would be considered "low level force"; but one would appear in police records designed to track these incidents, while in another record-keeping system it would not. At the very least - and methodologically speaking - the two different tracking policies (Sherman 2013) create a comparability issue between forces. The disparities illustrate the implications on police accountability and particularly around the transparency and the reporting of use of force, which continuous to be a contentious area in policing (Lersch et al 2008; Pate et al 1993; Terrill 2001; Garner et al 2006; Wolf et al 2009). This problem is exacerbated when many forces, including West Midlands Police where the present study took place, have stopped requesting their officers to log use of force reports completely (West Midlands Police and Crime Commissioner 2014). The only forms of systematic tracking available in many police forces, across the United Kingdom, are through custody arrest records, or non-computerized pocketbooks, or particular force types such as TASER discharges or lethal weapons:

31. There is no longer a requirement for officers to record a use of force on a separate form in relation to open hand techniques, CS spray and baton strikes. 
Officers are instructed to record the detail of any incident, force used and the rationale supporting the application based on the NDM in their pocket notebooks.

32. The decision to stop recording such data was taken in late 2010 after consultation with Force Health and Safety, Professional Standards and Operations and was ratified by Command Team. Form WG 433 (use of force form) was withdrawn to support the force aim of reducing bureaucracy and reducing repetition of data.

33. Records are maintained on the deployment of firearms officers, TASER usage and police dog bites.

\section{THE BIRMINGHAM SOUTH BODY-WORN CAMERAS EXPERIMENT}

\section{Experimental Settings}

The trial was conducted with the Birmingham South Local Policing Unit (LPU) in the West Midlands Police (WMP) force area. Birmingham South is a largely residential area populated by roughly 286,000 residents from a wide range of socio-economic levels, but with a limited range of ethnicities in comparison to other areas of the West Midlands (Birmingham City Council 2015). The trial was a field randomized controlled trial (RCT) utilizing 46 response officers, and ran over a period of six months between June and December 2014. To emphasize, however, the officers did not serve as the units of analysis.

\section{Unit of Analysis}

Although ideally officers would have been randomized to treatment and control groups on a 50/50 basis, making the officer the unit of analysis, this was not practicable, operationally speaking but methodologically as well as. Whilst the majority of officers work in solo formations, operational need within emergency response units often requires ad hoc, double crewing when responding to more complicated incidents. This means that officers in the control group could have been 'contaminated' by responding to calls together with members of the treatment group. As the treatment is hypothesized to affect the interaction with members of the public, 'control officers' would have had their behaviours altered in response to the presence of their colleagues' BWCs. At the very least, suspects and victims would behave differently when BWCs are present - even if only some officers are wearing them (e.g., Jennings et al 2015). To 
use a medical analogy, this is similar to a clinical trial where both the treatment and control patients are sharing the same pill.

A further consideration was the sample size. A sample size of only 46 officers would have possibly generate an underpowered study (Cohen 1988), or one that was "doomed to failure' (Clarke and Weisburd 1994:179). Increasing the number of officers was not a realistic aim for our study. Under these circumstances, a sample size of 46 officers would only just have been sufficient if we were looking to detect quite large effects $(d=0.8)$ with a probability of 0.05 and a power at $80 \%$. Based on the available evidence (e.g., Ariel, Farrar \& Sutherland 2014; Ariel et al 2016b), the anticipated effect size of BWCs on use of force is small to medium (Cohen 1988).

Instead, by making police temporal shifts (e.g., 07:00-17:00 shift) the unit of analysis much like the original Rialto study (Ariel, Farrar \& Sutherland 2014) and as designated in its experimental protocol (Ariel and Farrar 2012), the sample size available can be increased significantly, therefore allowing for a much smaller effect size to be detected (Cohen 1988). As we ran the trial for 26 weeks, we were able to randomly assigned 430 shifts into treatment and control conditions (with a 50/50 split). Using $\mathrm{G}^{*}$ Power (Faul et al 2007), this sample size was sufficient to detect a smaller effects $(d=0.3$; Cohen 1988) with a probability of 0.05 and a power at $80 \%$.

Admittedly, this method might still have produced some residual contamination from the treatment groups being carried into the control shift. The same officers either used BWCs or did not use BWCs in treatment and control shifts, respectively. There is the potential that behavioural modifications due to treatment conditions 'carried through' into control conditions. If BWCs effect behaviour, then there may be a learning mechanism at play, where officers adapted their overall behaviour (and possibly attitudes), and this broader change affected control conditions as well. At the same time, the degree of contamination is more limited (than using officers as the unit of analysis, for instance), because at least the spill over does not directly affect those that the police interact with: suspects, victims and witnesses. From a theoretical perspective, BWCs have at least as much of an effect on citizens as they do on officers. Therefore, if there is a spill over effect of the intervention, it is specific to one party only.as such, this design allows us to be in a better position to characterise SUTVA violations (see Sampson 2010). Ultimately, given the rule of maximin (Rawls 1971) and the inherent 
operational policing pressures, shift randomization was deemed the best possible option, for these circumstances. For further methodological discussions about temporal shifts as a unit of analysis in policing studies, see Ariel, Farrar and Sutherland (2014) as well as Ariel et al (2016d).

\section{Random Allocation Procedure}

The random allocation of shifts was provided to the sergeants on a weekly basis using the Cambridge Randomizer (Ariel, Villa and Sherman 2012), on a pseudo-randomization basis with 1:1 allocation of day and night shifts, including days of the week (Table 1). No baseline significant differences emerged $\left(\chi^{2}=17.50 ; \mathrm{p}=.354\right)$. These treatment and control shift sequences were communicated to the patrol officers, who would be deployed to patrol with or without the BWCs. Over the course of the six months trial, 215 shifts were allocated to treatment and 215 to control conditions.

Table 1 Here

\section{Treatment and Experimental Procedure}

The trial began with a two-week exploratory test, so the officers could familiarize themselves with the equipment, the design of the experiment and the various processes involved. Technical problems were also resolved during this period. Once the RCT commenced and the random allocation sequence was communicated to the teams, then while on treatment shifts officers were issued cameras, whereas while on control shifts the cameras remained in the police station.

Additional details of the trial procedures can be found in our pre-trial experimental protocol (see Supplementary Materials A). However, we highlight two important aspects of the procedure. First, during every beginning of a shift, the officer in charge was responsible for assuring treatment integrity (e.g., gearing all patrolling officers with BWCs on treatment shifts, and making sure that officers were not going on patrols wearing BWCs during control shifts). 
On treatment shifts, constables wearing BWCS would go out on patrol, and record their interactions with suspects, arrestees, victims and witnesses, based on the experimental protocol. At the end of each shift, the officers returned to the station and docked the cameras in a specially designated room. The docking procedure uploaded the evidence into storage and charged the battery of the camera.

Second, the treatment included not only the wearing of BWCs during all encounters between police and members of the public, but prior to any interaction officers were requested to announce the presence and use of the camera. As more fully elaborated on in Ariel et al (2016a, 2016b), the verbal communication was hypothesised to create a deterrent effect against both officers as well as suspects. In addition, the particular type of camera used in this trial included a front-facing screen, which the party that interacts with the police office can see himself or herself whilst the camera is turned on (see Picture 1 below).

\section{Picture 1 Here}

\section{Manipulation Checks}

Treatment integrity was checked by a police inspector on a daily basis, to ascertain that the random allocation sequence was preserved. These daily supervisor's reviews, including regular checks of the officers' data uploads, revealed 99\% compliance with random allocation, in both treatment and control conditions. In practice, treatment integrity was continuously measured, and any miss-assignments that occurred during the trial were immediately dealt with and therefore nearly never reoccurred. ${ }^{1}$ Furthermore, an Inspector also routinely randomly dipsampled custody records and informed officers that such a procedure was put in place, thus ensuring that officers were continuously aware that an auditing exercise was maintained. These manipulation checks were put in place so that treatment fidelity is maintained, and that reported use of force was accurately recorded as well.

\footnotetext{
${ }^{1} 46$ officers $* 430$ shifts $=19,780$ officers' shifts, however excluding rest days (known prior to random assignment), the actual total amount of officers shifts randomly assigned into the experimental arms were 18,224. Of those, mis-assignment was detected in 182 officers' shifts, over the course of 26 weeks.
} 


\section{Variables}

Crimes and calls for service data for the study were recorded by West Midlands Police, in accordance with Home Office Counting Rules (Home Office 2014). In order to recover the data required for the study, a police software program called Discoverer $4 i$, a standard tool used by West Midland Police analysts to harvest data from all police systems, was utilized. Discoverer $4 i$ was particularly useful in determining whether arrests were made during treatment or control shifts.

As noted in our review, systematic recordings of incidents of use of force are not routinely captured by most UK forces, and West Midlands Police is no different. An initial consideration, that of returning to the manual recording of use of force forms, by officers, was vetoed due to well-documented difficulties in maintaining this process and bias in recording from officers (Alpert and Smith 1999:63). Systematic social observations were outside the scope of the RCT as well. Instead, independent recordings of use of force do routinely take place in the arrest custody suite, by the custody officer. These records are kept in custody recording system, or "ICIS". The custody officer is legally required to register, among other details, what type of force was used by the arresting officer. To emphasize, the independent custody officer captured this information following an interview s/he conducts with both the arrestee as well as the arresting officer. This short survey includes questions about injuries sustained by the arrestee, whether s/he is ill, etc. See Supplementary Materials B for a template of the electronic form that custody officers complete for every 'booking'.

Specifically for use of force, the custody officer's report includes a record of each category, which mimics the force continuum: (1) verbal commands, (2) compliant handcuffs, (3) physical restraint/forcible handcuffs, (4) CS Spray, (5) baton and (6) Taser. Note that in this recording policy there is a clear distinction between compliant and forcible handcuffing by the arresting officer.

\section{Statistical Procedures}

With the data, we had two binary variables that each had only two possible levels (counts of observations at each level), displayed in a 2 X 2 binary proportions table. Therefore, 
we used Odds Ratios ("OR") to assess the differences and to compare the responses (Y: the outcome variables) according to the value of the explanatory variable (X: BWC or controls). We therefore used the total arrest counts as the denominator (post-random assignment) and the number of force events within the post-treatment period as the numerator, and computed the OR. We also measured $95 \%$ confidence internals associated with these point estimates.

We run two statistical models for these main effects. First, we observed the treatment effect on all force categories lumped together as 'either or' variable (as in all previous BWCs experiments). Second, we modelled the treatment effect after removing from the dependent variables 'compliant handcuffing' as a use-of-force category, for the reasons we explained above.

Next, we carried out this procedure several times, for each type of use of force response: (a) physical restraints, (b) non-compliant handcuffs, (c) batons, (d) CS, (e) TASER drawn, (f) TASER used, and (g) Police dogs. To emphasise, these are official categories of force responses in West Midlands Police. Therefore, these should not be considered as exploratory secondary analyses (Assman et al, 2000).

Finally, accepting that "force responses" move up on the force continuum as the level of force applied to the subject increases, several force types could be applied in each case. It is not rare for officers to use both physical restraints, with handcuffs and potentially TASER discharge as well, "against" the same combatant suspect. Therefore, we computed an overall weighted score, based on the cumulative ordinal position of each tactic, using a scale based on the force continuum scale, where " 1 " is assigned to compliant handcuffing and up to " 8 " for the use of a police dog (Table 3). The weighted scores were then used as dependent variables of the effect of BWCs.

Notice that we place emphasis on effect sizes, rather than statistical significance testing, given the growing awareness in scientific papers that that treatments should be evaluated based on the impact rather than the .05 alpha criterion. Effect sizes provide a more substantive answer to the efficacy question of any intervention. As recently commented by the editorial unit of the Cochrane Collaboration (2014), "results should not be reported as statistically significant or statistically non-significant [as] the cut-off point of $5 \%$ is arbitrary... In general, point estimates and confidence intervals, when possible... should be used to describe effects based on the size of the effect and the quality of the evidence." Uman (2011:57) noted that: 


\begin{abstract}
"In contrast to traditional hypothesis testing which can give us information about statistical significance (i.e., did the intervention group differ from the control group) but not necessarily clinical significance (i.e., was this difference clinically meaningful or large), effect sizes measure the strength of the relationship between two variables, thereby providing information about the magnitude of the intervention effect (i.e., small, medium, or large).
\end{abstract}

In tune with this growing line of methodological approach, we also focused on the magnitude of the differences between BWCs conditions and non-BWCs conditions, rather than p-values, but present the associated 95\% confidence intervals. For a more in depth read on these methodological issues, see Fan \& Konold (2010), Greenland et al (2016), Kirk (2001), Thomas, Salazar \& Landers (1991), Ziliak \& McCloskey (2008, 2016).

\title{
RESULTS
}

As noted, during the course of the six months, 215 shifts were randomly allocated to treatment and 215 to control, totalling 18,224 officer hours. Four hundred and five individual incidents of police use of force were recorded in Birmingham South, out of a cohort of 590 arrests (270 arrests during treatment conditions and 320 during control conditions). Overall, there were 224 incidents of use of force recorded when cameras were not present and 181 when cameras were. However, once "compliant handcuffs" were excluded, 56 and 106 incidents of use of force were recorded in treatment and control conditions, respectively (Figure 1).

We tested for the comparability of these arrests. The assignment of officer-shifts to experimental and control condition was random, fewer arrests are made during treatment (270) than during control conditions (320). We therefore tested whether different conditions and situations emerged during treatment versus control arrests, beyond the question of use of force. Our analyses (Table 2) indicate that the differences in arrests can be attributed to random variations in the data. As shown, the situations that led to arrests were not statistically significantly different - in terms of time of day, day of week, prevalence of drunk suspects, or possession of drugs. Likewise, we found no statistically significant concentrations of any type of condition 'within' officers $\left(\chi^{2}(195)=228.1 ; \mathrm{p}<.05\right)$; see Supplementary Materials C).

Table 2 Here 
Model I: overall effects with compliant handcuffs - The odds for use of force per arrests when BWCs are present compared to BWCs not-present conditions are about $14 \%$ lower, ranging between $43 \%$ lower and $29 \%$ greater odds compared to the odds of use of force under control conditions. These results are not significantly different $\{\mathrm{OR}=.856 ; 95 \% \mathrm{CI} .567$, $1.292\}$.

Model II: overall effects without compliant handcuffs - The odds for use of force incident per arrests under the second model are about $48 \%$ and significantly lower $\{\mathrm{OR}=.523$; $95 \%$ CI .339, .807\}. Put differently, the odds of a use of force incident beyond compliant handcuffing, when BWCs are not present, are double than when BWCs are present.

\section{Figure 1 Here}

Table 3 below lists the raw number of use of force incidents, by type. Notice that the number of use of force "types" exceeds the prevalence counts (240 in treatment and 334 in control conditions), since more than one type of force can be applied in the same forceful encounter (i.e., a combination of several force responses "against" the same suspect).

The pre-specified breakdown of police use of force categories (Fig. 2) indicates substantial differences in physical restraint and non-compliant handcuffing, as well as in terms of compliant handcuffs. However, the directionality of these effects is reversed. BWCs seem to lower the odds of physical restraints by $52 \%\{\mathrm{OR}=.476 ; 95 \% \mathrm{CI} .304, .754\}$ and non-compliant handcuffing by $49 \%\{\mathrm{OR}=.507 ; 95 \% \mathrm{CI} .319, .805\}$. On the other hand BWCs seem to 
increase the odds of compliant handcuffing by nearly $40 \%$ \{ $\mathrm{OR}=1.405 ; 95 \%$ CI $.961-2.055$, $\mathrm{p}=.079\}^{2}$, compared to control conditions.

Figure 2 Here

Looking more closely at other force responses, we note that categories of police use of force above physical restraint represent only $5 \%$ of total police use of force in this sample (Fig. 2). If these results are indicative, they tend to suggest that BWCs increase the odds of force responses (Fig. 2); however, these conclusions are suspect, given their low rates of occurrence.

Finally, in terms of the cumulative use of force scores (see Table 4 and Fig. 3), there is, in comparing treatment and control conditions, a significant increase in the ordinal position of force when the data is arranged as a weighted, cumulative score. Our estimates suggest a $35 \%$ reduction of overall weighted force in the treatment conditions compared to control conditions.

Table 4 and Figure 3 Here

\section{DISCUSSION}

In this experiment, we robustly tested the effect of BWCs in non-US settings, with one of the UK's largest police forces. Over a six-month period, using the officers' shifts as the unit of analysis, we have contributed to the evidence in three major ways. First, we demonstrated that the use of BWCs in police operations reduces both the prevalence and the severity of police use of force, in a country where police use of force is substantially less lethal than it is in countries like the United States (Sherman 24/2/2015). This suggests that when the police use BWCs, police use of force can be curbed down in "aggressive" police-public contacts that do not involve life-threatening situations, for both officers as well as suspects.

\footnotetext{
${ }^{2}$ See Sherman and Weisburd (1995:637) for a justification for more relaxed p-value criteria in policing experiments
} 
Perhaps more importantly, our study exemplifies the importance granular analysis of pre-specified outcome variations (see Ariel \& Farrington 2010). Overall, our weighted dependent variable, which captures any type of force response, shows a $35 \%$ reduction in the use of force, compared to control conditions. However, the findings suggest that BWCs can be shown to be more efficient when recording force in one way, but not in another. The way force is defined is crucial: when "police use of force" includes what the professional literature refers to as "compliant handcuffing" of suspects - meaning the ordinary handcuffing of arrestees when transporting them to jail - then our overall estimated effects are non-significant and weaker. However, when the definition of "police use of force" excludes such handcuffing, the odds for force responses were cut in half compared to control conditions.

Moreover, once we break down "force" into its components, we are then able to characterize the effect in more specific terms. Our findings suggest that the overall pooled effect on use of force is driven by low-level force categories, rather than more aggressive tactics. We first show that BWCs increases compliant handcuffing. We then show that the odds for physical restraints and non-compliant handcuffs were lower with BWCs than control conditions. Next, our data illustrate that the odds for using more combative force responses, such as batons, TASER, or police dogs, were nonsignificant and therefore the effect is presently unclear. Thus, there is a distinct change when moving from 'empty handed' techniques to ones where 'force tools' are used. This suggests that once the level of force reaches the rare, but elevated levels of force, the effect of BWCs is less discernible. However, given the nonsignificant results in these upper force categories - a finding which is likely to emerge due to the small number of overall incidents that officers in Birmingham South applied such tactics - more research is required before reaching firm conclusions on the effects of BWCs in these types of force.

\section{Interpreting the Effect of BWCs on Compliant Handcuffing}

The granular analysis of the dependent variable - police use of force - indicated $40 \%$ greater odds for compliant handcuffs when BWCs were used compared to the odds under control conditions. This is the opposite of what we have detected for noncompliant handcuffing (51\% reduction). How can these contradictory results, in terms of compliant and non-compliant handcuffing, be explained? If BWCs are meant to deter, under what circumstances might they 
actually increase the prevalence of use of force, rather than decrease it? An increase in use of force is counterintuitive to the hypothesized effect of BWCs. It goes against the premise of deterrence theory, which can potentially explain the effects of BWCs. We offer three interpretations.

1. BWCs create unintended consequences. On the one hand, it is possible that wearing a BWC intensifies, rather than lowers, the tension between some officers and some suspects. If this is the case, officers may have to apply compliant handcuffs more frequently when BWCs are in use because the devices trigger aggression, for particular suspects. Under these circumstances, the handcuffs are used pre-emptively. For instance, the cameras can make certain suspects verbally abusive or hostile towards the officer (though not physical), and so the officer immediately responds with compliant handcuffs without which he would have to resort to tougher force responses. To emphasize, the officer would not have to resort to tougher force responses and consequently to use pre-emptive handcuffing, if BWCs were not present.

There is some general evidence to support this argument: use of force does not occur in isolation and, ordinarily, police officers use force as a reaction to the demeanour of the suspect (Rojek et al 2012, Terrill \& Mastrofski 2002; Garner et al 2002; Alpert and Dunham 1997; Alpert et al, 2004; Terrill 2001). Officers are trained to match appropriate force against subject resistance, and they would move up the force continuum along with the way that the suspect exhibited such behaviour (College of Policing 2013). However, the key is the officer's perception that more force is appropriate under the circumstances. Therefore, as the only difference between treatment and control conditions is the presence of BWC, then we could draw the conclusion that, in order to gain control of situations that may otherwise end up with more severe types of force responses, officers understood the encounter as one that merits the use of compliant handcuffing.

On the other hand, the unintended consequences explanation does not fully expound why we measured a substantial decrease in the odds for ordinary use of force categories while the odds for compliant handcuffing rates increased. If officers use compliant handcuffs at increasing rates during control conditions because they pre-empt assault against them, this could mean that BWCs may reduce overall use of force, but at the same time increase the likelihood of assaults against officers. This suggests that BWCs are potentially backfiring in terms of assaults against the police, and WMPs officers have found a way to deal with it: to 
increase the rates of pre-emptive handcuffs of arrestees. Therefore, the overall results mask a more complicated story: under certain conditions and for some suspects, BWCs increase rather than decrease levels of aggression, and a way to operationally deal with this problem is to place these suspects in handcuffs, before they turn this aggression into violence. How officers are able to predict which suspects are more likely to assault them (e.g., drugged offenders), or whether in fact there are case types that require these compliant handcuffs (e.g., domestic assaults), remains unclear at this stage $\mathrm{e}^{3}$, and more research is needed at this granular level.

2. Transparency and Accountability. A more parsimonious interpretation would suggest that the increase in the use of compliant handcuffs is simply a reporting artefact. With the new BWCs policy, officers (including the custody officers) began logging compliant handcuffs more diligently under the treatment conditions. Ariel (2016) contextualizes this pattern within the police accountability and transparency literature. In this regard, accurate and full reporting of use of force is a clear marker of enhanced accountability; democratic institutions must hold their functionaries responsible for their actions, justified or otherwise, so we require from them better recordings (Walker \& \& Archbold 2013; Skonick \& Fyfe 1993).

Once BWCs are mandated in police operations, reporting of use of force incidents increases, especially where they are normally underreported. This is less of an issue with more severe force responses, as it is very unlikely that a TASER discharge, the use of batons or police dogs could go unreported in large western police departments. However, lower bound force responses are easier to conceal, and even more so if there is no legal requirement to report them - such as compliant handcuffing or voice commands. Thus, officers in the treatment group began registering these incidents at increased rates per arrests, compared to control conditions. What once was left to ad hoc explanations by officers who did not record "lesser" types of force, now can no longer be hidden from the radar.

If this transparency mechanism is at play behind the increased in the odds of reporting compliant handcuffing, then we can conclude that BWCs have caused officers to become more

\footnotetext{
${ }^{3}$ Legal advice comes from the ACPO Guidance on the use of Handcuffs (2010:5): "In establishing an objective basis for believing that a person may escape or attempt to escape, an officer or member of police staff may reach to whatever the person says or does, but need not wait for a physical act [...] In establishing an objective basis for believing that a person should be handcuffed because violence is likely to be used against the officer, member of police staff or a member of the public, the officer or member of police staff need not wait for a physical act from the person."
} 
accountable. The likelihood of "getting caught" using this type of lesser force - now on videotape - has substantially increased. As a result, the rates of reporting went up.

3. 'Regimented Police Behaviour'. An alternative explanation, which fits comfortably within the construct of deterrence theory, is that the increase in compliant handcuffing is an unintended consequence of "being observed". As the awareness of being scrutinized and observed generally evokes a measurably favourable shift in behaviour (see our review above), it is conceivable that the increase of compliant handcuffing indicates that officers follow the rules of police conduct prescriptively. This means that the officer with BWCs is acting regimentally, in a 'policeman-like' behaviour, which includes the handcuffing of arrestees. This is an adverse consequence, because it removes the need to show that the handcuffing was "reasonable, necessary and proportionate" because now the arrest event itself is construed as "the objective basis for the decision to apply handcuffs" (ACPO Guidance 2010).

At the same time, this mechanism can be construed as a desired consequence. We want our officers to follow rules. The increased odds of handcuffing under treatment conditions can be interpreted as a fairer policy: to handcuff every arrestee, with limited discretion to decide if the arrest warrants handcuffing or not. This can be seen as the essence of a distributive fairness approach (Tankebe 2013).

\section{Policy Implications}

There is a wealth of studies suggesting that legitimate police use of force contributes to a wider public acceptance of the legitimacy of policing (Mawby 2002, Goldsmith 2005, Manning 2010; Reiner 2010). Some incidents of police use of force can irreparably damage the police/public contract, leading to catastrophic outpourings of violence against the state. The Dallas shootings of 07/07/2016 are examples thereof. These may only represent a tiny fraction of one percent of the number of times officers use force on members of the public, and the intimate details of why and how the incident flared-up into violence is not always captured in third party recordings because the confrontation does not excite public interest until it becomes heated. These kinds of conflicts demand rules for the police officer but none for the citizen (Vunak, 2001) and so invariably resemble a street brawl. Video footage of these kinds of events strongly influence the level of the community's trust and confidence and may become a catalyst for what was seen in the UK in 2011 and in Ferguson, Missouri in 2014. If BWCs indeed lessen 
the incidence of police use of force, or at least some forms of it. The ramifications of a lessening of the use of force cannot be underestimated.

Over a number of years, there have been numerous attempts to inhibit police misconduct, from policy changes and training through to civilian oversight committees. Mostly these have been ineffective (Walker 2005). The question of whether, and how much, force is used, one that requires decision making during police-public encounters, is the most difficult police behaviour to influence (Chan 1997, 1999; Ericson 2007). Our study has shown there is an effective tool for accomplishing this, with BWCs.

Finally, it is important to ensure that an efficient BWC policy is adopted by police departments. One major element of such policy would be strict guidelines in which officers will be required to announce the presence of the camera. This may fit legal requirements about recording interactions with members of the public, but more importantly in order to materialize the deterrence threat. If the reading of the Caution or Miranda Rights warning is required in order to echo the rights of the suspect to protect against involuntary self-incrimination (UK officers must give notice of arrest and the crime as soon as reasonably possible; College of Policing, 2015; US Supreme Court 13/05/1991); then a BWC policy must include a clear warning as soon as operationally feasible. It is a combination of this awareness and recognition of the technology that changes behaviours, practically as well as legally, and a sound policy should secure the theoretical mechanisms with such an immediate warning.

\section{Limitations of Study}

This study has been conducted on a relatively small scale with only 46 officers, albeit there were 430 shifts randomized to control and treatment. We measured 'only' 19 arrests that used higher levels of force, which has made it difficult to provide stronger estimates of the treatment effects. Only a much larger or longer study would be able to detect smaller effects, for these less frequent events. We invite further research to consider this possibility.

This study has also ignored the actual conflict point in these scenarios. There is still no robust understanding of the demeanour hypothesis as it pertains to BWCs (see Ariel et al 2014; Jennings et al 2015). There was no opportunity to either review the recorded footage of each incident, or interview the parties involved. Even if access was granted to the footage, observing 
recorded footage clearly would be observational and partial only, as we cannot view incidents during control conditions. This leaves us speculating, whether the camera operates on one or both of the parties involved, and whether the cameras affect the officers' behaviour and then affecting the offender, or the opposite direction. There may be a double effect. We simply do not know. It would be very difficult, time consuming and expensive to study the mechanism at play in these conflict scenarios, but it could be a valid direction for future research.

\section{CONCLUSIONS}

Any level of force exercised by the police over the public can strain relations and "a single critical incident can have deleterious consequences" (Jefferis et al 1997:392). Technology can help reduce the need for force, and the BWC offers such a medium. Experimental evidence from Birmingham South shows that BWCs reduce the odds of use of force in arrests by about $50 \%$, which echoes the findings found in the Rialto Experiment. However, this replicated result was only achieved when we removed from the use of force measure compliant handcuffs. Future studies will be required to pay closer attention to the way force is defined, as the effect of BWCs is conditional on the way "force" is operationalized - with compliant handcuffs versus without compliant handcuffs, open handed versus force apparatus, etc. Our test shows that the treatment effect is concentrated in the lower bounds of the force continuum, with a non-significant effect on more aggressive force categories. BWCs seem to increase accountability and transparency, particularly on those police responses for which there is no requirement to $\log$ reports. 


\section{REFERENCES}

ACPO (Association of Chief of Police Officer of England, Wales \& Northern Ireland) (2010). Guidance on the Use of Handcuffs. Available at http://tinyurl.com/zm45nfs [last accessed 20 July 2017].

Adams, K. (1996) Measuring the prevalence of police abuse-of-force. In: Geller W and Toch H (eds) Police violence: understanding and controlling police abuse-of-force. Yale University Press, New Haven, pp 52-93.

Alpert, G.P. and Dunham, R.G. (1997) The force factor: measuring police use-of-force relative to suspect resistance. Police Executive Research Forum, Washington.

Alpert, G.P. and Dunham, R.G. (eds) (2004) Understanding police use-of-force: officers, suspects, and reciprocity. Cambridge University Press, Cambridge.

Alpert, G.P., Dunham, R.G. and MacDonald, J.M. (2004) Interactive police-citizen encounters that result in force. Police Quarterly 74:475-488.

Alpert, G.P., Smith, W.C. (1999) Police Use of Force Data: Where we are and Where We Should Be Going. Police Quarterly. 2:1. 57-78.

Ariel, B. (2016a). Technology in Policing: The Case for Body-Worn Cameras and Digital Evidence. The Police Chief Magazine. International Association of Chiefs of Police

Ariel, B. (2016b). Increasing Cooperation With The Police Using Body Worn Cameras. Police Quarterly

Ariel, B. (2016c). Police Body Cams Give Mixed Results and We Don't Know Why. IEEE Spectrum

Ariel, B., \& Farrington, D. P. (2010). Randomized block designs. In Handbook of quantitative criminology (pp. 437-454). Springer New York.

Ariel, B., Farrar, W. A., \& Sutherland, A. (2015). The effect of police body-worn cameras on use of force and citizens' complaints against the police: A randomized controlled trial. Journal of Quantitative Criminology, 31(3), 509-535.

Ariel, B., Farrar, W.A. (2012). 'Rialto Police Department Wearable Cameras Experiment.' Retrieved 15th September 2015 from http://www.crim.cam.ac.uk/research/ experiments/rexpost/rialto.pdf.

Ariel, B., Sutherland, A., Henstock, D., Young, J., Drover, P., Sykes, J., Megicks, S., Henderson, R. (2016a). Wearing Body-Cameras Increases Assaults Against Officers and Do Not Reduce Police-Use of Force: Results From A Global Multisite Experiment. European Journal of Criminology

Ariel, B., Sutherland, A., Henstock, D., Young, J., Drover, P., Sykes, J., Megicks, S., Henderson, R. (2016b). Increases in police use-of-force in the presence of body-worn cameras are driven by officer discretion: a protocol-based sub-group analysis. Journal of Experimental Criminology

Ariel, B., Sutherland, A., Henstock, D., Young, J., Drover, P., Sykes, J., Megicks, S., Henderson, R. (2016c). Why do police body-worn-cameras "work"? Considerations for future research and implementation. Policing: A Journal of Policy and Practice

Ariel, B., Sutherland, A., Henstock, D., Young, J., Drover, P., Sykes, J., Megicks, S., Henderson, R. (2016d). "Global Multi-Site Randomized Controlled Trial Shows that Police Body-Worn- 
Cameras Reduce Citizen's Complaints against the Police: A Case of "Contagious Accountability"?" Criminal Justice and Behavior

Ariel, B., Vila, J. and Sherman, L. (2012) Random assignment without tears: how to stop worrying and love the Cambridge randomizer. Journal Experimental Criminology 82:193-208.

Assmann, S. F., Pocock, S. J., Enos, L. E., \& Kasten, L. E. (2000). Subgroup analysis and other (mis)uses of baseline data in clinical trials. The Lancet,355(9209), 1064-1069.

Ayoob, M.F. Stress fire. Gunfighting for police: Advanced tactics and techniques. Police Bookshelf, Concord, NH. 1984

Baker, M. (1985) Cops: their lives in their own words. Fawcett, New York.

Barclay: (2004) Trustworthiness and competitive altruism can also solve the "tragedy of the commons"'. Evolution and Human Behaviour. 254:209-220.

Bayley, D. H. (1996). Police for the Future. Oxford University Press.

Bayley. D.H. and Garofalo, J. (1989) The management of violence by police patrol officers. Criminology 271:1-26.

BBC News (24/10/2013) "Police 'cameras on cops' plan for all patrol officers." Retrieved 19th April from http://www.bbc.co.uk/news/uk-24662243

BBC News (3/06/2015) 'Metropolitan Police officers to get 20,000 body cameras.' Retrieved 14th September from http://www.bbc.co.uk/news/uk-england-london-32991516

BenBucato.com (03/12/2014) 'Cameras on Cops and Junk Science in Rialto'. Retrieved 14th September from $h t t p: / / w w w$. benbrucato.com/? $p=633 \#$ more-633

Birmingham City Council. (n.d.) 2015 'Population and Census.' Retrieved 14th September from http://www.birmingham.gov.uk/cs/Satellite $? c=$ Page \&childpagename $=$ Planning-and-

Regeneration\%2FPageLayout \&cid $=1223096353895$ \& pagename $=B C C \% 2 F C$ ommon $\% 2 F W r a$ pper\%2FInlineWrapper

Bittner, E. (1970) The functions of the police in modern society. Oelgeschlager, Gunn and Hain, Cambridge

Black D (1976) The Behavior of Law. Academic Press, New York

Brown, A. (1998) Police governance in England and Wales. Cavendish, London.

Brown, G. R. (2015). The Blue Line on Thin Ice: Police Use of Force Modifications in the Era of Cameraphones and YouTube. British Journal of Criminology.

Cannon, W.B. and Cranefield P.F. (1915) Bodily Changes in Pain, Hunger, Fear, and Rage: An Account of Recent Researches into the Function of Emotional Excitement. New York: D. Appleton.

Chan, J. (1999) Governing Police Practice: Limits of the New Accountability. British Journal of Sociology, 50: 251-79.

Chan, J. (1997) Changing Police Culture: Policing in a Multicultural Society. Cambridge University Press.

Chartrand, T.L. and Bargh, J.A. (1999) The chameleon effect: the perception-behaviour link and social interaction. Journal of Personality and Social Psychology. 766:893. 
Clarke, R.V., Weisburd, D. (1994) Diffusion of crime control benefits: observations on the reverse of displacement. Crime Prevention Studies 2:165-184

Cochrane Collaboration (2014). Results should not be reported as statistically significant or statistically non-significant. See http://editorial-unit.cochrane.org/blog/results-should-not-bereported-statistically-significant-or-statistically-non-significant

Cohen, J. (1988) Statistical power analysis for the behavioral sciences, 2nd edn. Lawrence Earlbaum Associates, Hillsdale.

College of Policing. (n.d.) 2014 'National Decision Model.' Retrieved 15th September 2015 from https://www.app.college.police.uk/app-content/national-decision-model/the-national-decisionmodel/

College of Policing. (n.d.) 2015 'Response, arrest and detention.' Retrieved 15th September 2015 from https://www.app.college.police.uk/app-content/detention-and-custody-2/response-arrestand-detention/

College of Policing. (n.d.) 2013 'Police use of force.' Retrieved 15th September 2015 from https://www.app.college.police.uk/app-content/public-order/core-principles-andlegislation/police-use-of-forcel

Collins, R. (2009) The micro-sociology of violence. The British Journal of Sociology. 60:3

Cordner, G. W. (1989). Police agency size and investigative effectiveness. Journal of Criminal Justice, 17(3), 145-155.

Croft, E.B. (1985) Police use-of-force: an empirical analysis. Doctoral dissertation, State University of New York at Albany.

Cubitt, T. I., Lesic, R., Myers, G. L., \& Corry, R. (2016). Body-worn video: A systematic review of literature. Australian \& New Zealand Journal of Criminology, 0004865816638909.

Desmedt, J. C. (1984). Use of force paradigm for law enforcement. Journal of Police Science and Administration, 12(2), 170-176.

DuCharme, S.D. (2001). Search for Reasonableness in Use-of-Force Cases: Understanding the Effects of Stress on Perception and Performance, The Fordham L. Rev., 70, 2515.

Durlauf, S.N., \& Nagin, D.S. (2011). Imprisonment and crime. Criminology \& Public Policy, 10(1), 13-54.

Dzieweczynski, T.L., Eklund, A.C. and Rowland, W.J. (2006) Male 11-ketotestosterone levels change as a result of being watched in Siamese fighting fish, Betta splendens. General and Comparative Endocrinology 1472:184-189.

Ellis, T., Jenkins, C. and Smith: (2014) The Impact of Personal Issue Body Worn Video Cameras on the Isle of Wight: Interim key findings. Presentation to BWCSG, Birmingham UK.

Engel, R. S., Sobol, J. J., \& Worden, R. E. (2000). Further exploration of the demeanor hypothesis: The interaction effects of suspects' characteristics and demeanor on police behaviour. Justice Quarterly, 17(2), 235-258.

Engel, R.S., Sobol, J.J., Worden, R.E. (2000) Further exploration of the demeanor hypothesis: the interaction effects of suspects' characteristics and demeanor on police behaviour. Justice Quarterly. 172:235-258.

Ericson, R. (2007) Rules in Policing: Five Perspectives, Theoretical Criminology. 11:367-401. 
Fabricatore, J., Azen, S., Schoentgen, S. and Snibbe, H. (1978) Predicting performance of police officers using the sixteen personality factor questionnaire. American Journal Community Psychology. 61:63-70.

Fan, X., \& Konold, T. R. (2010). Statistical significance versus effect size.International encyclopedia of education, 7, 444-450.

Farrar, W. (2013) Self-Awareness to Being Watched and Socially-Desirable Behavior: A Field Experiment on the Effect of Body-Worn Cameras and Police Use-of-Force. Washington, DC: Police Foundation.

Faul, F., Erdfelder, E., Lang, A.G., Buchner, A. (2007) G*Power 3: a flexible statistical power analysis program for the social, behavioral, and biomedical sciences. Behavioural Research Methods 39:175-191.

Fyfe, J.J. (1988) Police use of deadly force: research and reform. Justice Quarterly. 52:165-205.

Garner, J.H., Maxwell, C.D. and Heraux, C.G. (2002) Characteristics associated with the prevalence and severity of force used by the police. Justice Quarterly 194:705-746.

Geller, W. and Toch, H. (1996) Police Violence: Understanding and Controlling Police Abuse of Force. Yale University Press, New Haven

Gervais, W.M. and Norenzayan, A. (2012) Like a camera in the sky? Thinking about God increases public self awareness and socially desirable responding. Journal of Experimental Social Psychology. 481:298-302

Goldsmith, A. (2005). Police reform and the problem of trust. Theoretical criminology, 9(4), 443470.

Goldsmith, A.J. (2010) Policing's New Visibility. British Journal of Criminology. 1:21.

Goodall, M. (2007) Guidance for the Police Use of Body-Worn Video Devices. London: Home Office.

Greater London Authority (24/06/2015). 'The Met to be questioned on rape investigations \& body worn cameras.' Retrieved 14th September 2015 from https://www.london.gov.uk Imedia/assembly-press-releases/2015/06/the-met-to-be-questioned-on-rape-investigationsbody-worn.

Greenland, S., Senn, S. J., Rothman, K. J., Carlin, J. B., Poole, C., Goodman, S. N., \& Altman, D. G. (2016). Statistical tests, P values, confidence intervals, and power: a guide to misinterpretations. European journal of epidemiology, 1-14.

Groff, E.R., Ratcliffe, J.H., Haberman, C.P., Sorg, E.T., Joyce, N.M., \& Taylor, R.B. (2015). Does what police do at hot spots matter? The Philadelphia Policing Tactics Experiment. Criminology 53(1), 23-53.

Guardian (01/06/2015) 'The Counted'. Retrieved 14th September 2015 from http://www.theguardian.com/us-news/ng-interactive/2015/jun/01/the-counted-police-killingsus-database

Haanstad, E. J. (2009). Violence and temporal subjectivity. Anthropology and Humanism, 34(1), 71-82.

Hickman, M.J., Piquero A.R., and Garner, J.H. (2008) Toward a national estimate of police use of nonlethal force. Criminology \& Public Policy 7.4 (2008): 563-604. 
Hinton, R. (2004) Statistics Explained 2nd Ed. Routledge. London

Home Office (2014). 'Home Office Counting Rules For Recording Crime.' Retrieved 19th April 2015

from

https://www.gov.uk/government/uploads/system/uploads/attachment_data/file/419533/countgeneral-april-2015.pdf

Home Office, Personal Safety Training (PST) (26/03/14). Retrieved 14th September 2015 from https://www.gov.uk/government/uploads/system/uploads/attachment_data/file/298583/PST_v3. OEXT.pdf

Hunt, J. (1985). Police accounts of normal force. Journal of Contemporary Ethnography, 13(4), 315-341.

Jefferis, E.S., Kaminski, R.J., Holmes, S. and Hanley, D.E. (1997) The effect of a videotaped arrest on public perceptions of police use-of-force. Journal of Criminal Justice 255:381-395.

Jennings, W. G., Lynch, M. D., \& Fridell, L. A. (2015). Evaluating the impact of police officer body-worn cameras (BWCs) on response-to-resistance and serious external complaints: Evidence from the Orlando police department (OPD) experience utilizing a randomized controlled experiment. Journal of Criminal Justice, 43(6), 480-486.

Jervis, R., Lebow, R.N., \& Stein, J.G. (1989). Psychology and deterrence. JHU Press.

Kahneman, D. (2011) Thinking, fast and slow. Farrar, Straus and Giroux, New York.

Katz, C. M., Choate, D.E., Ready J.R., \& Nuňo, L. (2014). Evaluating the Impact of Officer Worn Body Cameras in the Phoenix Police Department. Phoenix, AZ: Center for Violence Prevention \& Community Safety, Arizona State University.

Kirk, R. E. (2001). Promoting good statistical practices: Some suggestions. Educational and Psychological Measurement, 61(2), 213-218.

Klepper, S. and Nagin, D. (2006) The deterrent effect of perceived certainty and severity of punishment revisited. Criminology. 274:721-746.

Kupferberg, N. (2008). Transparency: A New Role for Police Consent Decrees. Colum. JL \& Soc. Probs., 42, 129.

Langworthy, R. H., and Travis, L. F. (1999).Policing in America: A balance of forces (2d ed.). Upper Saddle River. New Jersey, Prentice Hall.

Las Vegas MPD (n.d.) 2011. 'Use of Force.' Retrieved 15th September 2015 from http://www.cops.usdoj.gov/pdf/Use-of-Force.pdf

Lawrence R. (2000) The Politics of Force: Media and the Construction of Police Brutality. University of California Press.

Lentz, S. A., and Chaires, R.H. (2007) The invention of Peel's principles: A study of policing 'textbook' history. Journal of Criminal Justice 35.1: 69-79.

Lersch, K. M., Bazley, T., Mieczkowski, T., \& Childs, K. (2008). Police use of force and neighbourhood characteristics: An examination of structural disadvantage, crime, and resistance. Policing \& Society, 18(3), 282-300.

Lester, D. (1996). Officer attitudes toward police use of force. In: Geller W, Toch H (eds) Police violence: understanding and controlling police abuse-of-force. Yale University Press, New Haven, pp. 180-190. 
Lum C, Koper C, Merola L, et al. (2015) Existing and ongoing body worn camera research: Knowledge gaps and opportunities. Report, The Laura and John Arnold Foundation. https://www.bja.gov/bwc/pdfs/BodyWornCameraResearch.pdf

Lum, C., K., C.S.; Merola, L.M., Scherer, A., Reioux, A. ( 2015). Existing and Ongoing Body Worn Camera Research: Knowledge gaps and opportunities. Report for the Laura and John Arnold Foundation

Manning, K. (2010). Democratic policing in a changing world. Boulder, CO: Paradigm Publishers

Margarita, M. (1980). Police as victims of violence. The Justice System Journal, 218-233.

Mastrofski, S. D. (2002). The romance of police leadership. Crime \& Social Organization, 153196.

Mawby, R.C. (2002), Policing Images: Policing, Communication and Legitimacy. Willan, Cullompton

McCahill, M. and Norris, C. (2002) CCTV in Britain Urbaneye, Working Paper no. 3. Centre for technology and Society, Technical University of Berlin.

Mesa Police Department (2012). On-Officer body camera program, Forensic protocols, Mesa Police Administration Manual, Mesa, AZ.

Miller, L., Toliver, J. and Police Executive Research Forum. (2014) Implementing a Body-Worn Camera Program: Recommendations and Lessons Learned. Washington, DC: Office of Community Oriented Policing Services.

Munger, K. and Shelby, J.H. (1989) Effects of an observer on hand washing in a public restroom. Perceptual and Motor Skills 693:733-734.

Nagin, D.S. (2013a) Deterrence in the twenty-first century. In Crime and Justice: A Review of Research, Vol. 42, ed. Michael Tonry. Chicago, IL: University of Chicago Press.

Nagin, D.S. (2013b) Deterrence: A review of the evidence by a criminologist for economists. Annual Review of Economics 5:83-105.

Nagin, D.S., Solow, R.M., \& Lum, C. (2015). Deterrence, Criminal Opportunities, and Police. Criminology, 53(1), 74-100.

New York Times (12/08/2013) 'Judge Rejects New York's Stop and Frisk Policy.' Retrieved 19th April 2015 from http://www.nytimes.com/2013/08/13/nyregion/stop-and-frisk-practiceviolated-rights-judge-rules.html?_r=0

New York Times (24/09/2014) 'Washington Police to Test Body Video Cameras.' Retrieved 14th September 2015 from http://www.nytimes.com/reuters/2014/09/24/technology/24reuters-usawashington-police-cameras.html

Newburn T. and Hayman S. (2002) Policing, Surveillance, and Social Control: CCTV and Police Monitoring of Suspects. Willan

Norris, C. and Armstrong, G. (1999) The maximum surveillance society. The rise of CCTV, Oxford: Berg.

ODS Consulting (2011) Body Worn Video Projects in Paisley and Aberdeen, Self Evaluation. Glasgow: ODS Consulting. 
Owens, C., Mann, D. and McKenna, R. (2014). The Essex Body Worn Video Trial: The impact of Body Worn Video on criminal justice outcomes of domestic abuse incidents. College of Policing. UK.

Pate, A. M., Fridell, L. A., \& Hamilton, E. E. (1993). Police use of force: Official reports, citizen complaints, and legal consequences, volumes I and II. Washington, DC: The Police Foundation.

Ransley, J., Anderson, J., \& Prenzler, T. (2007). Civil litigation against police in Australia: Exploring its extent, nature and implications for accountability. Australian \& New Zealand journal of criminology, 40(2), 143-160.

Rawls, J. (1971) A Theory of Justice. Harvard University Press, Cambridge, MA (1971).

Ready, J. T., \& Young, J. T. (2015). The impact of on-officer video cameras on police-citizen contacts: findings from a controlled experiment in Mesa, AZ. Journal of Experimental Criminology, 11(3), 445-458.

Reddit, (24/12/2014) 'First scientific report shows police body-worn-cameras can prevent unacceptable use-of-force.' Retrieved 14th September from https://www.reddit.com $/ r /$ news/comments/2q9k2n/first_scientific_report_shows_policel

Regoli, R. M., Crank, J. P., \& Culbertson, R. G. (1989). Police cynicism, job satisfaction, and work relations of police chiefs: An assessment of the influence of department size. Sociological Focus, 22(3), 161-171.

Reiner, R. (2010). The politics of the police. Oxford University Press.

Reiss, A.J. (1968) Police brutality-answers to key questions. Society 58:10-19.

Rojek, J., Alpert, G. P., \& Smith, H. P. (2010). Examining officer and citizen accounts of police use-of-force incidents. Crime \& Delinquency, 58(2), 301-327.

Sherman, L. W. (2013). The rise of evidence-based policing: Targeting, testing, and tracking. Crime and Justice, 42(1), 377-451.

Sherman, L. W., \& Berk, R. A. (1984). The specific deterrent effects of arrest for domestic assault. American sociological review, 261-272.

Sherman, L. W., Gottfredson, D. C., MacKenzie, D., Eck, J., Reuter:, Bushway, S. (1998) Preventing Crime: What Works, What Doesn't, What's Promising: A Report to the United States Congress. U.S. Department of Justice, Office of Justice Programs, Washington, DC.

Sherman, L. W., Strang, H., Mayo-Wilson, E., Woods, D. J., \& Ariel, B. (2015). Are restorative justice conferences effective in reducing repeat offending? Findings from a Campbell systematic review. Journal of quantitative criminology, 31(1), 1-24.

Sherman, L.W. (1980) Causes of police behaviour: the current state of quantitative research. Journal of Research in Crime and Delinquency. 171:69-100.

Sherman, L.W. (24/02/2015) 'Police use of force: White House told US must learn from UK.' Retrieved 15th September from http://www.cam.ac.uk/research/news/police-use-of-forcewhite-house-told-us-must-learn-from-uk\#sthash.FVZWNRIL.dpuf

Sherman, L.W., \& Weisburd, D. (1995). General deterrent effects of police patrol in crime "hot spots": A randomized, controlled trial. Justice Quarterly, 12:4, 625-648 
Sherman, L.W., Strang, H. (2010) Doing experimental criminology. In: Gadd, D, Karstedt, S, Messner, S (eds) Handbook of criminological research methods. Sage, Thousand Oaks, CA.

Skogan, W. (2006), "The promise of community policing", in Weisburd, D. and Braga, A.A. (Eds), Police Innovation: Contrasting Perspectives, Cambridge University Press, Cambridge, pp. 27-43.

Skolnick J.H. (2008) Enduring Issues of Police Culture and Demographics. Policing and Society. Vol. 18, Iss. 1, 200

Skolnick, J.H. and Fyfe, J.J. (1993) Above the law: police and the excessive use-of-force. Free Press, New York.

Sproull, L., Subramani, M., Kiesler, S., Walker, J.H. and Waters, K. (1996) When the interface is a face. Human-Computer Interaction. 112:97-124.

Stenning: (2009). Governance and accountability in a plural policing environment-The story so far. Policing, 3(1), 22-33.

Strang, H. (2012) Coalitions for a common purpose: managing relationships in experiments. Journal of Experimental Criminology. 8(3):211-225.

Stratton, M., Clissold, and Tuson, R. (2014) The Promise of Body Worn Video: Considering the Evidence. Edmonton Police Service Body Worn Video Pilot Project.

Tankebe, J. (2013). Viewing things differently: The dimensions of public perceptions of police legitimacy. Criminology, 51(1), 103-135.

Terrill, W. (2001) Police coercion: application of the force continuum. LFB Scholarly Pub LLC, New York.

Terrill, W. and Mastrofski, S.D. (2002) Situational and officer-based determinants of police coercion. Justice Quarterly. 192:215-248.

Terrill, W., Paoline, E.A., \& Manning K. (2003). Police Culture and Coercion. Criminology, 41(4), 1003-1034.

Thomas, J. R., Salazar, W., \& Landers, D. M. (1991). What is missing in p<. 05? Effect size. Research quarterly for exercise and sport, 62(3), 344-348.

Tilley, N. (1993) Understanding car parks, crime, and CCTV: evaluation lessons from safer cities. Home Office Police Department, London.

Uman, L. S. (2011). Systematic reviews and meta-analyses. Journal of the Canadian Academy of Child and Adolescent Psychiatry, 20(1), 57.

University of Cambridge. 24/2/15 'Police use of force: White House told US must learn from UK.' Retrieved 15th September from http://www.cam.ac.uk/research/news/police-use-of-forcewhite-house-told-us-must-learn-from-uk\#sthash.FVZWNRIL.dpuf

US Justice Dept Press Release. 1/05/15 'Justice Department Announces \$20 Million in Funding to Support Body-Worn Camera Pilot Program.' Retrieved 14th September from http://www.justice.gov/opa/pr/justice-department-announces-20-million-funding-supportbody-worn-camera-pilot-program

US Supreme Court 13/05/2015. County of Riverside v. McLaughlin (89-1817), 500 U.S. 44 (1991). Retrieved 14th September from https://www.law.cornell.edu/supct/html/89-1817.ZO.html 
Von Hirsch, A., Bottoms, A.E., Burney, E. and Wikstrom O. (1999) Criminal deterrence and sentence severity: an analysis of recent research. Hart, Oxford.

Vunak: (2001). Anatomy of a street fight. Burbank, CA: Unique.

Walker S. (2007). Police Accountability: Current Issues and Research Needs. Paper presented at the National Institute of Justice (NIJ) Policing Research Workshop: Planning for the Future, Washington, DC.

Walker S. (2005). The New World of Police Accountability. Sage

Walker, S.E., \& Archbold, C.A. (2013). The new world of police accountability. Sage Publications.

Walsh, W. F. (2001). Compstat: An analysis of an emerging police managerial paradigm. Policing: An International Journal of Police Strategies \& Management, 24(3), 347-362.

Warwickshire PCC's Office. (5/6/2015) 'Report on unannounced visit to police custody suites in Warwickshire and West Mercia.' Retrieved 15th September 2015 from http://www.warwickshire-pcc.gov.uk/wp-content/uploads/2014/12/2015.06.05-Ltr-to-Rt-HonT-May-Report-on-Unannounced-Inspection-Visit-to-Police-Custody-Suites.pdf

Wasserman, H. M. (2014). Moral Panics and Body Cameras. Wash. UL Rev. Commentaries (Nov. $18,2014), 14-31$.

Weber Brooks, L., \& Leeper Piquero, N. (1998). Police stress: does department size matter?. Policing: An International Journal of Police Strategies \& Management, 21(4), 600617.

Weisburd D, Lum CM, Petrosino A (2001) Does research design affect study outcomes in criminal justice? Annals of American Academy of Political and Social Science. 578(1):50-70.

Welsh, B.C. and Farrington, D.P. (2009) Public area CCTV and crime prevention: an updated systematic review and meta-analysis. Justice Quarterly 264:716-745.

West Midlands Police and Crime Commissioner (2/12/2014) 'Use of Force Report to Strategic Policing and Crime Board'. Retrieved 14th September 2015 from http://westmidlandspcc.gov.uk/media/355722/07-spcb-02-dec-14-use-of-force.pdf

West Yorkshire Police (19/04/2011) 'Use of Force Policy' Retrieved 15th September 2015 from http://www.westyorkshire.police.uk/sites/default/files/files/disclosurelogs/2014_218_foi2014514185_use_of_force_policy2.pdf

White, M. D. (2014) Police Officer Body-Worn Cameras: Assessing the Evidence. Washington, DC: Office of Community Oriented Policing Studies.

Wicklund, R.A. (1975) Objective self-awareness. Advances in Experimental Social Psychology. 8:233-275.

Wikstrom, P-OH, Oberwittler, D., Treiber, K. and Hardie, B. (2012) Breaking rules: the social and situational dynamics of young people's urban crime. Oxford University Press, Oxford

Wilson, C., Willis, C., Hendrikz, J.K., Le Brocque, R. and Bellamy, N. (2010) Speed cameras for the prevention of road traffic injuries and deaths. Cochrane Database Syst Rev 11.

Wilson, J.Q. (1968) Varieties of Police Behaviour: The Management of Law and Order in Eight Communities. Cambridge, MA. Harvard University Press. 
Wolf, R., Mesloh, C., Henych, M. and Thompson, F. (2009) "Police use of force and the cumulative force factor". Policing: An International Journal of Police Strategies and Management. Vol. 32 Iss: 4, pp.739 - 757

Worden, R. E., \& Shepard, R. L. (1996). Demeanor, crime, and police behaviour: a reexamination of the police services study data. Criminology, 34(1), 83-105.

Worden, R. E., Shepard, R. L., \& Mastrofski, S. D. (1996). On the Meaning and Measurement of Suspects' Demeanor Toward the Police: A Comment on" Demeanor and Arrest". Journal of Research in Crime and Delinquency, 33, 324-332.

Worden, R.E. (1996) The causes of police brutality: theory and evidence on police use-of-force. In: Geller W, Toch H (eds) Police violence: understanding and controlling police abuse-of-force. Yale University Press, New Haven, pp 23-51.

Young, J.T., Ready, J.T. (2015) The impact of on-officer video cameras on police-citizen contacts: findings from a controlled experiment in Mesa, AZ. Journal of Experimental Criminology. 114.

Ziliak, S. T., \& McCloskey, D. N. (2008). The cult of statistical significance: How the standard error costs us jobs, justice, and lives. University of Michigan Press.

Ziliak, S.T., \& McCloskey, D.N. (2016). Lady Justice Versus Cult of Statistical Significance Oomph-less Science and the New Rule of Law. The Oxford Handbook of Professional Economic Ethics, 352. 
TABLE AND FIGURES

Table 1: Baseline Comparability of Shifts: Treatment vs. Control

$\underline{\text { Treatment }}$

Monday

Tuesday

Wednesday

Thursday

Friday

Saturday

Sunday

Total Shifts
21

17

18

19

16

16

21

128

\section{Control}

19

21

22

19

22

20

17

140

\section{Table 2: Treatment vs. Control Arrest Conditions}

\begin{tabular}{lccc} 
& $\begin{array}{c}\text { Treatment } \\
(\mathbf{n = 2 7 0})\end{array}$ & $\begin{array}{c}\text { Control } \\
(\mathbf{C = 3 2 0})\end{array}$ & $\begin{array}{r}\text { Chi-Square / T- } \\
\text { test scores }\end{array}$ \\
\hline Percent weekend & 123 & 151 & $\chi^{2}=35.00^{\wedge}$ \\
\hline Mean Time of Arrest & $45.6 \%$ & $47.2 \%$ & $\mathrm{t}=1.370$ \\
\hline Count/Percent of suspects reported drunk & $13: 05$ & $12: 28$ & $\chi^{2}=6.00$ \\
\hline Count/Percent of cases with drugs in possession & $40.70 \%$ & $39.40 \%$ & \multirow{2}{*}{$\begin{array}{c}2 \\
\end{array}$} \\
\hline
\end{tabular}

${ }^{*} \mathrm{p}<.05 ;{ }^{* *} \mathrm{p}<.01 ;$ day of week X arrest cross-tabulation 
Table 3: Use of Force Pre-Specified Categories - Treatment vs. Control Conditions

\begin{tabular}{lcccc}
\hline & Treatment & Rate per arrests & Control & Rate per arrests \\
\hline Compliant Handcuffs & 136 & 0.5037 & 134 & 0.4188 \\
\hline Physical Restraint & 49 & 0.1815 & 101 & 0.3156 \\
\hline Non-compliant Handcuffs & 45 & 0.1667 & 90 & 0.2812 \\
\hline Baton & 0 & -- & 0 & -- \\
\hline CS Spray & 1 & 0.0037 & 2 & 0.0063 \\
\hline Taser Drawn & 7 & 0.0259 & 4 & 0.0125 \\
\hline Taser Used & 2 & 0.0074 & 2 & 0.0063 \\
\hline Police Dog & 0 & 0.0000 & 1 & 0.0031 \\
\hline
\end{tabular}

Table 4: Cumulative Use of Force Weights - Treatment vs Control conditions

Counts Weighted Scores Cumulative Scores

\begin{tabular}{|c|c|c|c|c|c|c|}
\hline & Treatment & Control & Treatment & Control & Treatment & Control \\
\hline Compliant handcuffing $(1)^{\wedge}$ & 136 & 134 & 136 & 134 & 136 & 134 \\
\hline Physical Restraint (2) & 49 & 101 & 98 & 202 & 234 & 336 \\
\hline Non-compliant handcuffing (3) & 45 & 90 & 135 & 270 & 369 & 606 \\
\hline Baton (4) & 0 & 0 & 0 & 0 & 369 & 606 \\
\hline CS (5) & 1 & 2 & 5 & 10 & 374 & 616 \\
\hline Taser - drawn (6) & 7 & 4 & 42 & 24 & 416 & 640 \\
\hline Taser - used (7) & 2 & 2 & 14 & 14 & 430 & 654 \\
\hline Police Dog (8) & 0 & 1 & 0 & 8 & 430 & 662 \\
\hline
\end{tabular}

${ }^{\wedge}$ Score in parentheses, based on the police use of force continuum 
Figure 1 - Use of Force Counts with and without Compliant Handcuffs 250

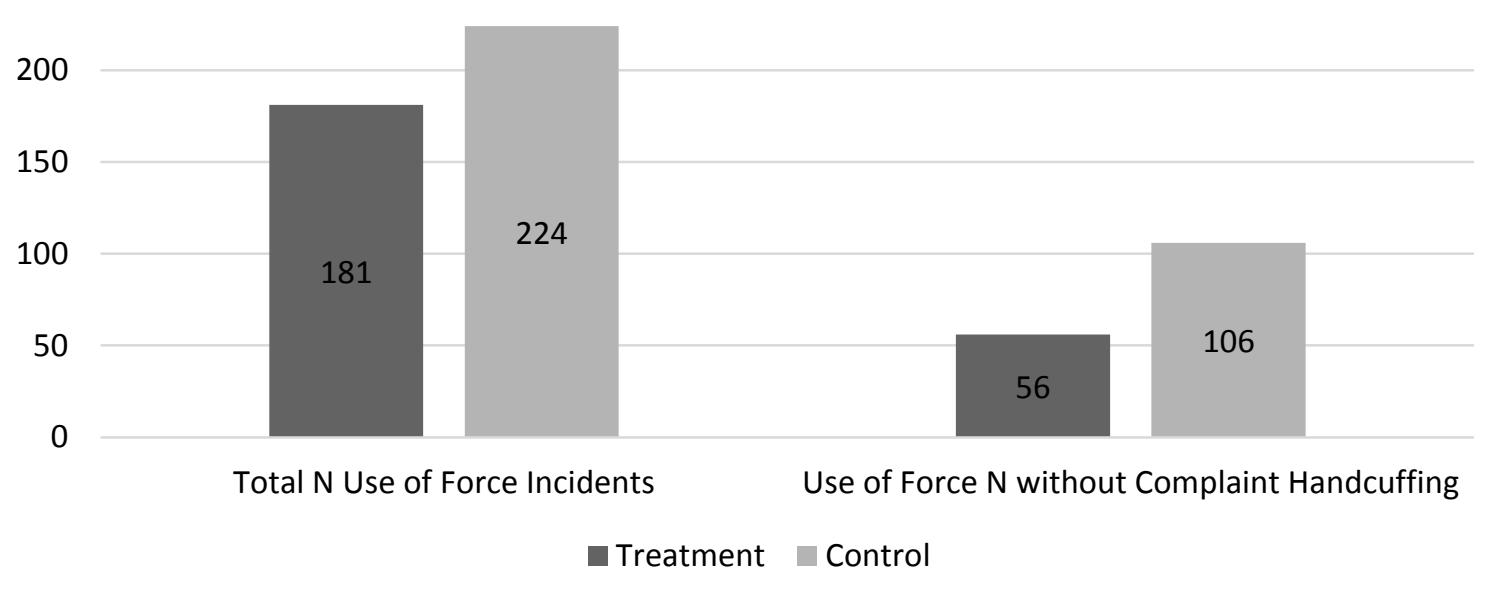

Fig. 2: Use of Force Rates per Arrests per Shift

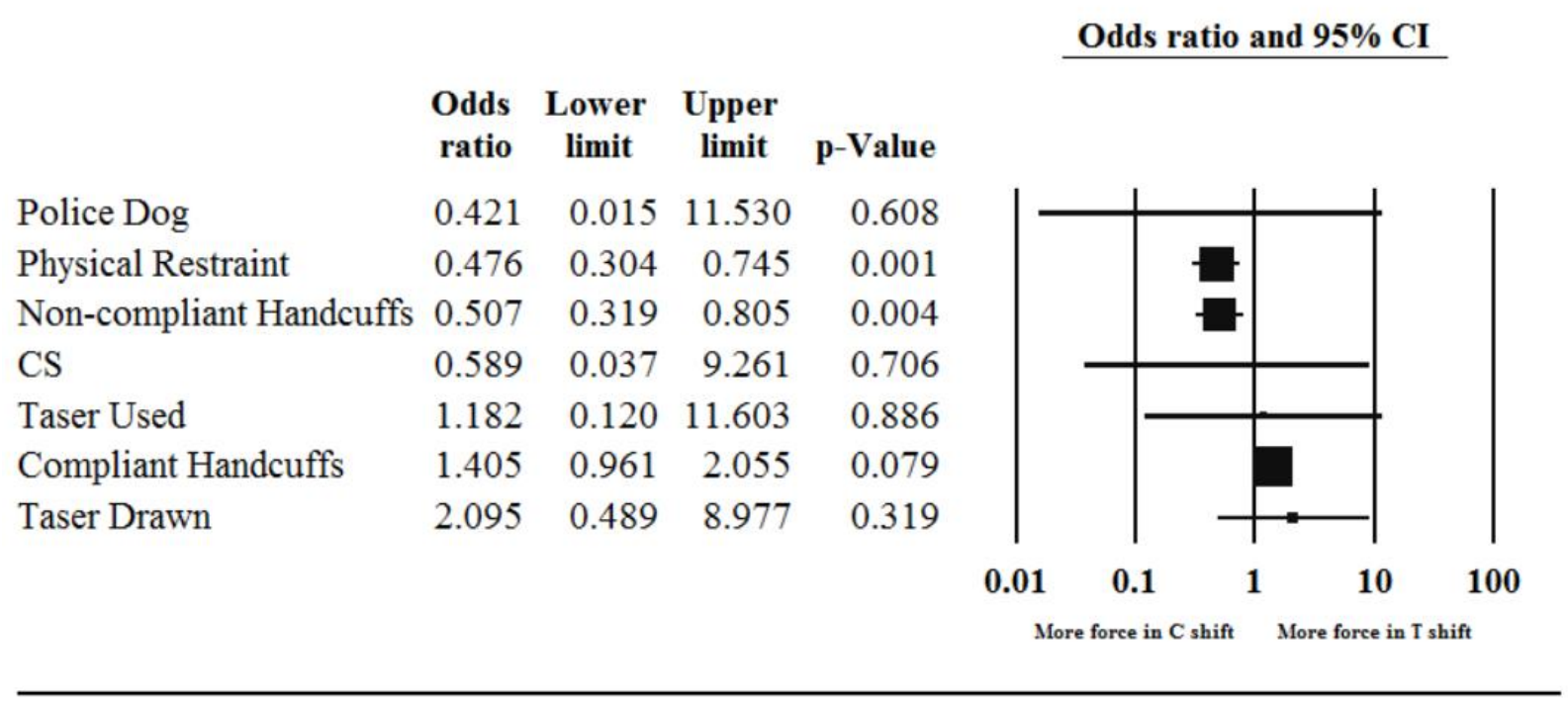


Figure 3 - Cumulative Scores

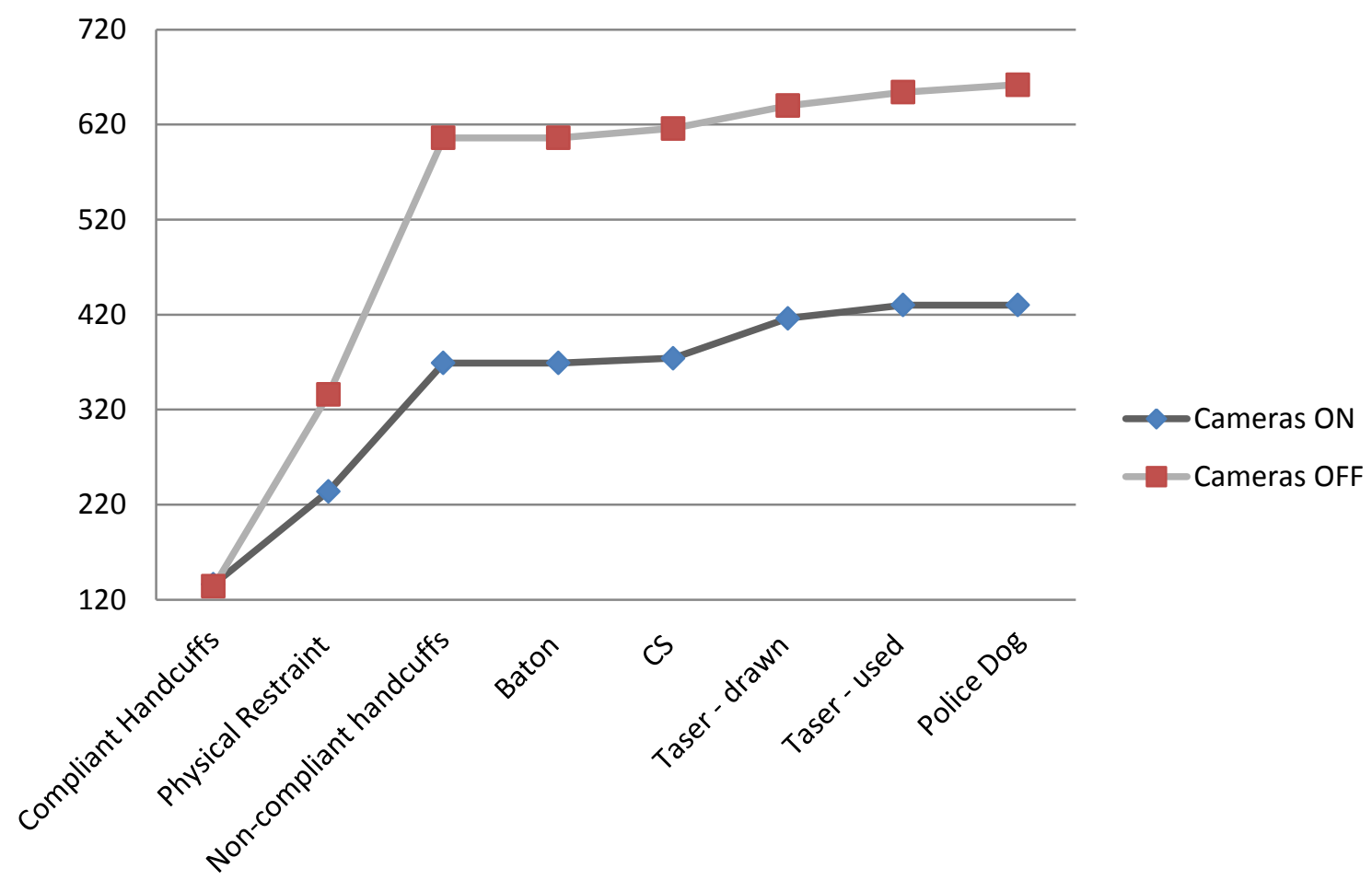


Picture 1: RevealMedia $\odot$ Front-Facing Body Worn Camera

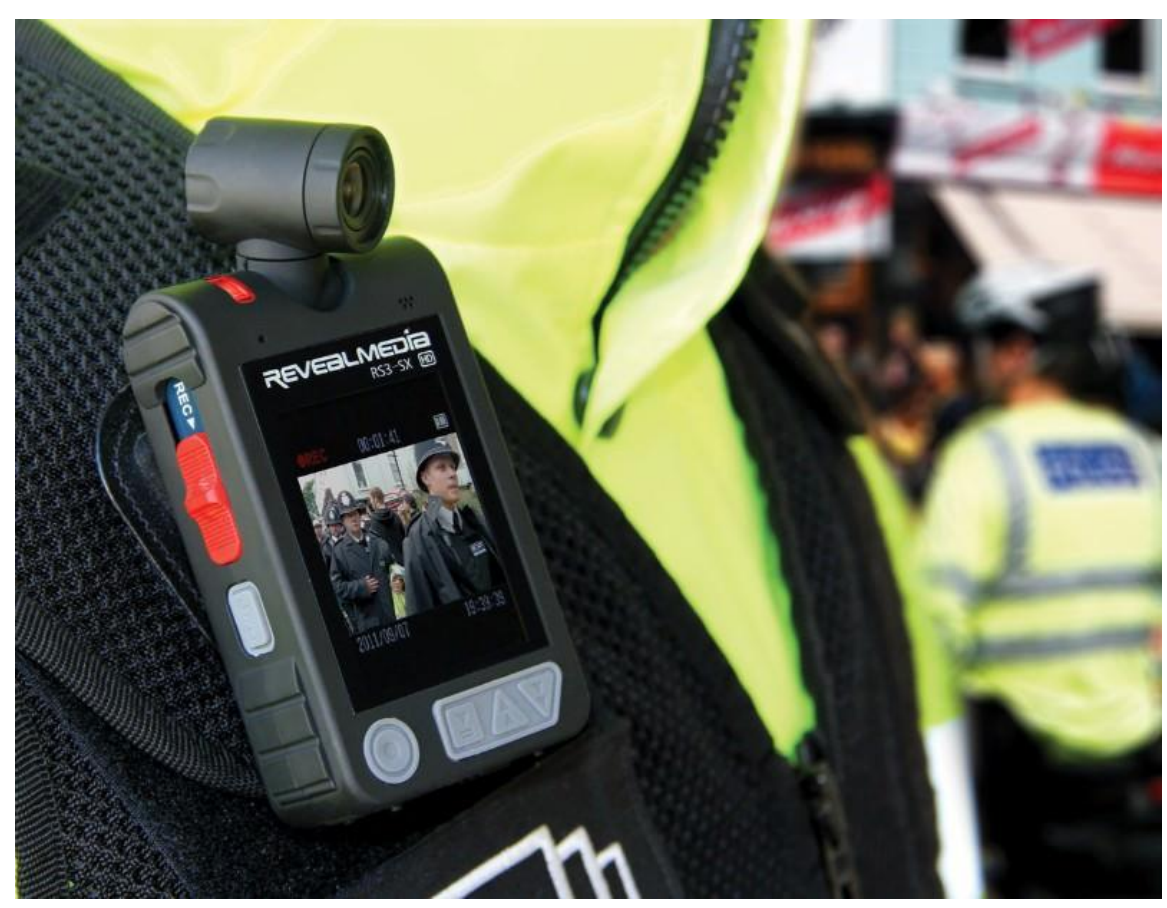


SUPPLEMENTARY MATERIALS A

(Attached pre-trial protocol) 
SUPPLEMENTARY MATERIALS B

त)

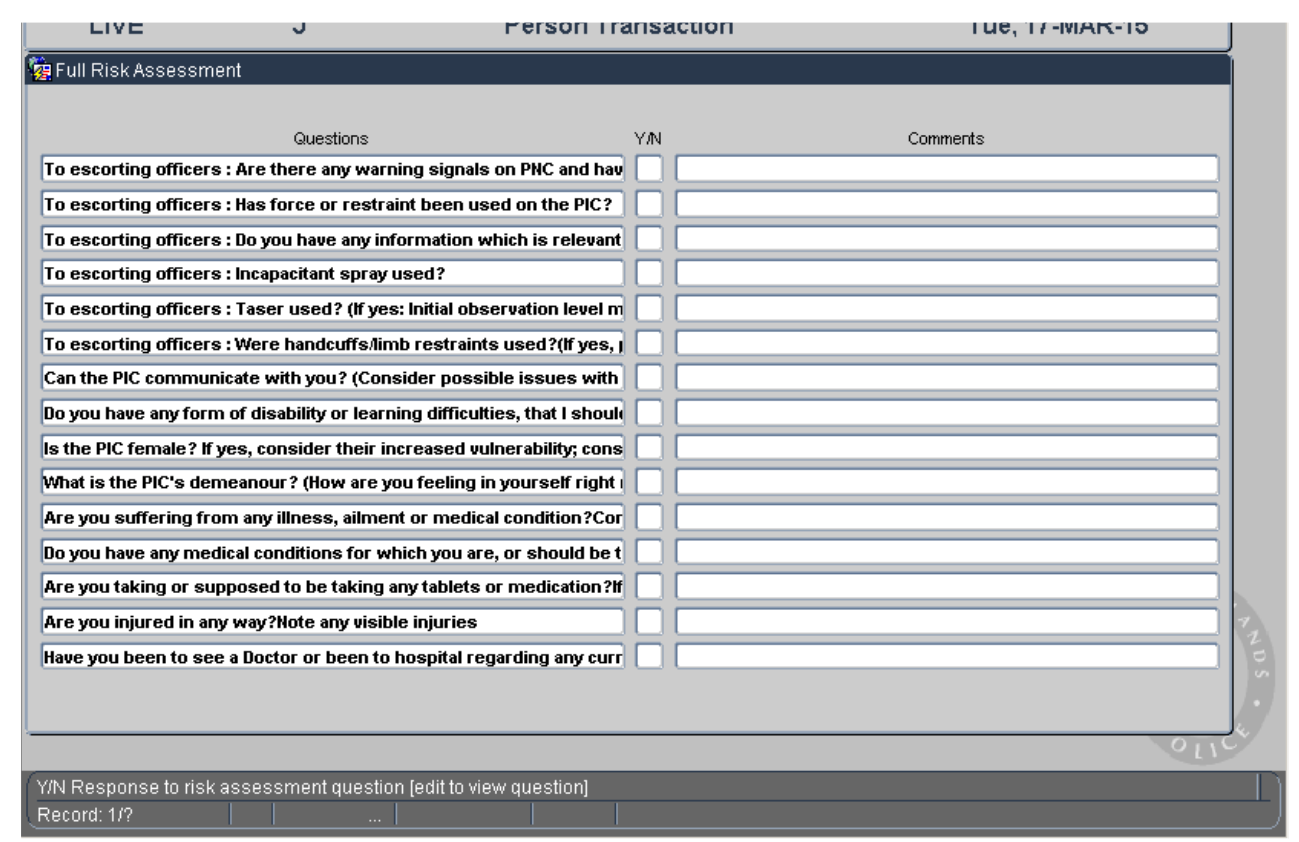




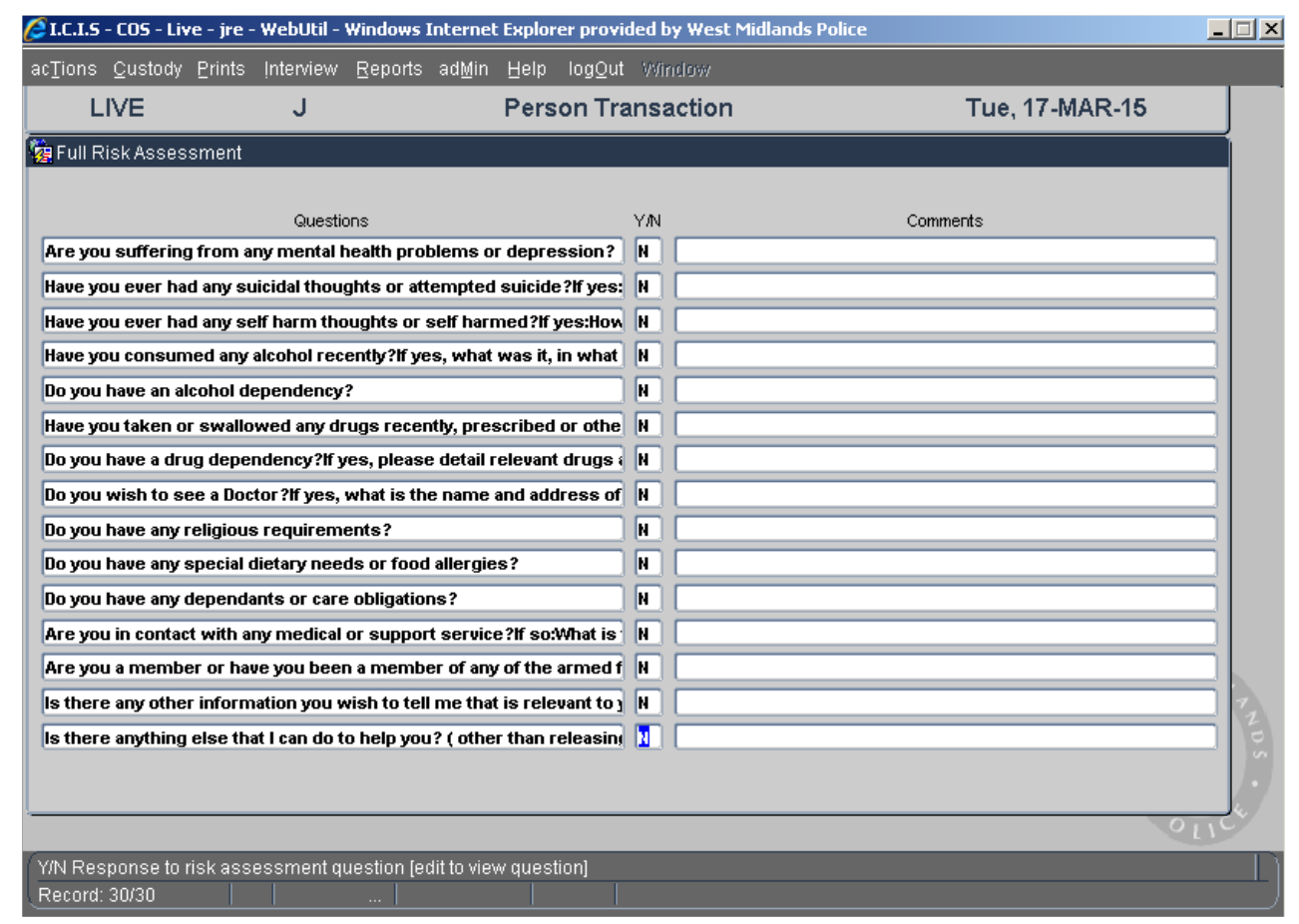


SUPPLEMENTARY MATERIALS C

\begin{tabular}{|c|c|c|c|c|c|}
\hline Officer & Arrest with BWCs & $\begin{array}{c}\text { Arrest without } \\
\text { BWCs }\end{array}$ & Total Arrests & Proportion & $\begin{array}{l}\text { BWCs : no } \\
\text { BWCs ratic }\end{array}$ \\
\hline Officer 1 & 1 & 3 & 4 & $1 \%$ & $33 \%$ \\
\hline Officer 2 & 12 & 13 & 25 & $4 \%$ & $92 \%$ \\
\hline Officer 3 & 12 & 10 & 22 & $4 \%$ & $120 \%$ \\
\hline Officer 4 & 5 & 10 & 15 & $3 \%$ & $50 \%$ \\
\hline Officer 5 & 4 & 3 & 7 & $1 \%$ & $133 \%$ \\
\hline Officer 6 & 0 & 1 & 1 & $0 \%$ & $0 \%$ \\
\hline Officer 7 & 10 & 15 & 25 & $4 \%$ & $67 \%$ \\
\hline Officer 8 & 2 & 2 & 4 & $1 \%$ & $100 \%$ \\
\hline Officer 9 & 7 & 12 & 19 & $3 \%$ & $58 \%$ \\
\hline Officer 10 & 4 & 6 & 10 & $2 \%$ & $67 \%$ \\
\hline Officer 11 & 4 & 3 & 7 & $1 \%$ & $133 \%$ \\
\hline Officer 12 & 7 & 4 & 11 & $2 \%$ & $175 \%$ \\
\hline Officer 13 & 6 & 2 & 8 & $1 \%$ & $300 \%$ \\
\hline Officer 14 & 9 & 9 & 18 & $3 \%$ & $100 \%$ \\
\hline Officer 15 & 8 & 11 & 19 & $3 \%$ & $73 \%$ \\
\hline Officer 16 & 6 & 10 & 16 & $3 \%$ & $60 \%$ \\
\hline Officer 17 & 1 & 2 & 3 & $1 \%$ & $50 \%$ \\
\hline Officer 18 & 5 & 1 & 6 & $1 \%$ & $500 \%$ \\
\hline Officer 19 & 5 & 7 & 12 & $2 \%$ & $71 \%$ \\
\hline Officer 20 & 2 & 1 & 3 & $1 \%$ & $200 \%$ \\
\hline Officer 21 & 1 & 2 & 3 & $1 \%$ & $50 \%$ \\
\hline Officer 22 & 2 & 6 & 8 & $1 \%$ & $33 \%$ \\
\hline Officer 23 & 7 & 12 & 19 & $3 \%$ & $58 \%$ \\
\hline Officer 24 & 4 & 7 & 11 & $2 \%$ & $57 \%$ \\
\hline Officer 25 & 9 & 5 & 14 & $2 \%$ & $180 \%$ \\
\hline Officer 26 & 8 & 7 & 15 & $3 \%$ & $114 \%$ \\
\hline Officer 27 & 5 & 3 & 8 & $1 \%$ & $167 \%$ \\
\hline Officer 28 & 6 & 12 & 18 & $3 \%$ & $50 \%$ \\
\hline Officer 29 & 5 & 10 & 15 & $3 \%$ & $50 \%$ \\
\hline Officer 30 & 14 & 10 & 24 & $4 \%$ & $140 \%$ \\
\hline Officer 31 & 5 & 9 & 14 & $2 \%$ & $56 \%$ \\
\hline Officer 32 & 0 & 1 & 1 & $0 \%$ & $0 \%$ \\
\hline Officer 33 & 9 & 11 & 20 & $3 \%$ & $82 \%$ \\
\hline Officer 34 & 5 & 2 & 7 & $1 \%$ & $250 \%$ \\
\hline Officer 35 & 0 & 2 & 2 & $0 \%$ & $0 \%$ \\
\hline Officer 36 & 1 & 0 & 1 & $0 \%$ & $-100 \%$ \\
\hline Officer 37 & 7 & 8 & 15 & $3 \%$ & $88 \%$ \\
\hline Officer 38 & 7 & 11 & 18 & $3 \%$ & $64 \%$ \\
\hline Officer 39 & 1 & 1 & 2 & $0 \%$ & $100 \%$ \\
\hline Officer 40 & 5 & 5 & 10 & $2 \%$ & $100 \%$ \\
\hline Officer 41 & 8 & 12 & 20 & $3 \%$ & $67 \%$ \\
\hline
\end{tabular}




\section{Officer}

Officer 42

Officer 43

Officer 44

Officer 45

Officer 46

Officer 47

Officer 48

Officer 49

\section{Arrest with BWCs}

4

2

4

8

10

16

3

4

Arrest without BWCs

\section{5}

0

6

9

10

14

11

$\chi^{2}(195)=228.1 ; p<.05$

Total Arrests Proportion

$2 \%$

$0 \%$

$2 \%$

$3 \%$

$3 \%$

$5 \%$

$2 \%$

$1 \%$
BWCs : noBWCs ratio $80 \%$ $-200 \%$ $67 \%$ $89 \%$ $100 \%$ $114 \%$ $27 \%$ $100 \%$

8

